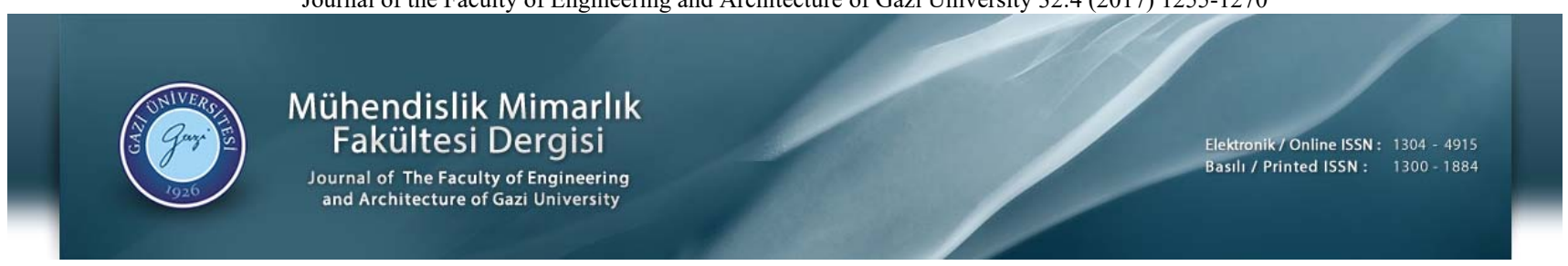

\title{
Eş zamanlı konum belirleme ve haritalama probleminde yeni bir durum tahmin yöntemi olarak parçacık akış filtresi
}

\author{
Erol Duymaz (D) 1*, Abdullah Ersan Oğuz (D)2, Hakan Temeltaş (D)1 \\ ${ }^{1}$ İstanbul Teknik Üniversitesi, Kontrol Mühendisliği Bölümü, Maslak, 34469, İstanbul, Türkiye \\ ${ }^{2}$ Hava Harp Okulu Dekanlığı, Elektronik Mühendisliği Bölümü, Yeşilyurt, 34149, İstanbul, Türkiye
}

\section{Ö N E Ç I K A N L A R}

- Parçacık akış filtresi tabanlı eş zamanlı konum belirleme ve haritalama

- Küresel konum belirleme (uydu yönbulum) sistemlerine erişimin olmadığı şartlar

- Parametrik olmayan filtre yapisı

Makale Bilgileri

Geliș: 11.08.2016

Kabul: 18.01.2017

DOI:

$10.17341 /$ gazimmfd.369697

Anahtar Kelimeler:

Parçacık akış filtresi, belirsizlik altında tahmin, eș zamanlı konum belirleme ve haritalama,

olasıllıksal sinyal ișleme, seyrüsefer

\section{ÖZET}

Son çeyrek yüzyılda ortaya çıkan Eş Zamanlı Konum Belirleme ve Haritalama (EZKH) problemi, 2000'li yıllardan başlayarak kara, deniz, hava platformları için uyarlanmış olmakla birlikte Kalman Filtresi tabanlı Genişletilmiş̧ Kalman Filtresi ve Dağıtılmış Kalman Filtresi gibi parametrik filtre yaklaşımları yanında Parçacık Filtresi gibi nonparametrik yöntemlerden oluşan durum tahmin yöntemleri, model ya da grafik tabanlı üst seviye kontrol amaçlayan ve özellikle de görüntü işleyen teknikler kullanılmıştır. Platform, araç, algılayıcı tipi ve kara, deniz, hava gibi ortam türü başlıklarında oldukça fazla farklılıklar göstermesi nedeniyle EZKH probleminin sınıflandırma yoluyla performans analizi ihtiyacından bahsedilebilir. İlk kez 2009 yılında ortaya konulan parçacık akış filtresi özellikle yüksek doğruluk ve hızlı yakınsama gibi avantajları nedeniyle ilgi görmüştür. Bu çalışmada literatürde ilk kez olarak Parçacık Akıs Filtresi tabanlı bir EZKH yapısı filtrenin matematik temelleri, filtre analizleri, otonom bir yer aracı ve algılayıcı modelini de içerecek şekilde verilmiştir. Belirsizlik altında tahmin araçlarının performans analizleri ile birlikte verilen benzetim sonuçlarına göre parçacık akış filtresi tabanlı EZKH performansı hesaplama maliyeti nedeniyle bazı gerçek zamanlı uygulamalardaki zorluklarına rağmen literatürde daha önce yer almış diğer tahmin yöntemleriyle karşılaştırıldığında daha başarılı sonuçlar verdiği, özellikle belirsizlikleri daha düşük algılayıcılar kullanan ölçüm ortamlarında parçacık filtresi yapısında ortaya çıkan dejenerasyon sorununu ortadan kaldırması nedeniyle tercih edilebileceği görülmüștür.

\section{Particle flow filter as a novel state estimation method for simultaneous localization and mapping problem}

\section{H I G H L I G H T S}

- $\quad$ Particle flow filter based simultaneous localization and mapping

- Global navigation satellite system-denied environment

- Non-parametric filter structure

Article Info

Received: 11.08.2016

Accepted: 18.01.2017

DOI:

10.17341/gazimmfd.369697

Keywords:

Particle flow filter,

estimation under uncertainty, simultaneous localization and mapping, probabilistic signal processing, autonomous navigation

\begin{abstract}
The Simultaneous Localization and Mapping (SLAM) problem, which emerged in the last quarter of the century, has been adapted for territorial, naval and aerial platforms starting from the year of 2000's and some parametric filter approaches such as Kalman Filter based Extended Kalman Filter and Distributed Kalman Filter, the stateestimation methods including nonparametric methods such as Particle Filter, some high level control aspiring, model or graphics-based and particularly image processing techniques has been used along with it. A strong need for performance analysis of the SLAM problem by classification can be mentioned, as it vary considerably in the platform, vehicle, sensor, and media type such as territorial, naval and aerial platforms. The particle flow filter, which put forward in 2009 for the first time, was particularly attractive due to its advantages such as high accuracy and fast convergence. In this research, a Particle Flow Filter based SLAM structure is given including mathematical bases/background of the filter, analysis, an autonomous ground vehicle and a sensor model, for the first time in the literature. According to the simulation results provided with the performance analysis of estimation under uncertainty tools/algorithms, although it has some computational complexity that may cause real time application concerns, the particle flow filter based SLAM performance is superior than other recursive state estimation approaches emerged before in the literature in terms of accuracy. Especially in the measurement environments with less uncertain sensors, it is preferable because it removes the problem of degeneration which arises in the particle filter structure.
\end{abstract}




\section{GİRIŞ (INTRODUCTION)}

Günümüz askeri sistemleri diğer sivil uygulamalarda olduğu gibi hedeflediği operasyonda kullanıcı ihtiyacını ortadan kaldıracak yenilikler peşindedir. Kara ve deniz ortamları araçları ile birlikte modern hava araçlarının da yerini yakın bir gelecekte insansız platformların alacağı beklendiğinden robotik, havacilık, uzay, elektronik, bilgisayar hatta endüstri mühendisliği sahalarında boy gösteren araştırmacılar İnsansız Sistemleri (İS) ilgi alanlarına almakta ve onlar için araç tasarımı ve kontrolü ile birlikte seyrüsefer konusunda da çalışmalar yürütmektedirler. Seyrüsefer ise optimal, güvenilir-çarpışmasız ve engellerden kaçınan rota planlaması algoritmalarını, konum belirleme-haritalama ve otonom seyrüsefer (navigasyon) gibi pek çok alanı içermektedir. İnsansız kara, deniz ve hava araçları yapısı gereği bir kullanıcı taşımadığından uzaktan kontrol edilmeye ihtiyaç duyar ancak bir haberleşme arızası, elektronik harp uygulaması ile iletişimin engellenmesi, kontrol mesafesinin dışında görev yapma ihtiyacı ya da tek bir kullanıcı tarafindan birden fazla aracın kontrolü gibi nedenlerle otonom hareket ihtiyacı ortaya çıkar. İlk otonom araçlar ve özellikle İHA çalışmalarında hava aracının başlangıç konumuna ya da belirlenen bir konuma geri dönmesi yeterli görülürken daha sonra özellikle askeri alanda verilen görevleri kendisi yerine getiren İHA sistemleri üretilmeye başlanmıştır. Bu amaçla otonom navigasyon yaparak verilen göreve uygun uçuş rotasını oluşturan, kendi kendine doğal engelleri aşan ve diğer araçlar ile haberleşerek bir filo görevi yerine getiren sistemler üzerinde yoğun çalışmalar devam etmektedir. Otonom seyrüseferin başarılı olması için İnsansız Sistemin konumunun doğru belirlenmesi ve içinde bulunduğu ortamın haritasının oluşturulması gerekir. Araç ortamdaki konumunu bildiği durumda algılayıcılarıyla ortam hakkında bilgi toplayıp ortamın haritasını oluşturabilir. Benzer şekilde ortamın haritasına sahip olan bir İnsansız Sistem de ortamdaki konumunu algilayıcılarıyla tespit edebilir. Konum ve ortam haritası bilgilerinden birini tam olarak tespit eden sistemler çoğu zaman diğer bilgiyi az hatayla tahmin edebilir. Ancak İnsansız Sistem konumunu ve ortam haritasını yeterince hassas olarak belirleyemezse, konum ve yönelimindeki hata zaman içinde birikimli olarak artar ve artan bu hatadan dolayı araç görev yapamaz ya da kaybolabilir.

Madencilik, arama kurtarma, yangın söndürme, denizaltı gibi sivil alanların yanı sıra askeri uygulamalarda ortam haritasının bilinmediği ya da herhangi bir nedenle küresel konum belirleme sistemlerine erişimin olmadığı şartlarda aracın kendi konumu belirleyip aynı zamanda harita oluşturması işlemi olarak tanımlanan EZKH kavramı SmithCheesman [1] tarafindan ortaya atılmış, Dissanayake [2], Bailey [3] ve Durrant-Whyte [4] gibi araştırmacılarca geliştirilmiş ve konsept haline getirilmiştir. Literatürde her iki kavram da geniş yer aldığından bu çalışma süresince Eş Zamanlı Konumlama (Konum Belirleme) ve Haritalama (EZKH) ile Simultaneous Localization and Mapping (SLAM) kavramları birbiri yerine kullanılabilecektir.

\section{1. Önceki Çalışmalar (Related Works)}

SLAM yaklaşımının temelleri Smith ve Cheesman tarafindan ortaya atılmış olmakla birlikte diğer ilk çalışmalarda, Andrade-Cetto vd. [5] tarafından Kalman filtresi (KF) tabanlı SLAM yapısında kısmi gözlenebilirlik etkisi araştırılmış, kararlılık ve tutarlılık problemleri ise Bailey vd. [6] tarafindan incelenerek SLAM alt problemlerine çözümler önerilmiştir [7]. Bu kapsamda uçak üzeri (airborne) SLAM uygulamalarına rastlamak da mümkündür [8]. Bu çalışmalarda otonom navigasyon için en doğru konumun ve haritaların oluşturulması oldukça önemli olmuştur [9]. SLAM araştırmacıları genişletilmiş (Extended Kalman Filter-EKF) ve dağıtılmış Kalman filtresi (Unscented Kalman Filter-UKF) gibi parametrik filtre yaklaşımları yanında parçacık filtresi (Particle Filter-PF) ve daha iyi performans hedefleyen türevi non-parametrik metotlar da kullanmış, Spruyt vd. [10] ise görüntü işleme temelli yöntemler üzerinde durmuşlardır [11]. Bunlardan Welle vd. [12] robot platformlarında parçacık filtresi tabanlı SLAM yapısını öngörmüş ve çalışmalarında haritalamayı Pioneer P3-AT robot üzerinde 3D laser scanner kullanarak gerçekleştirmiş iken diğer bazı çalışmalar ise görüntü ve platform boyutu gibi değişkenlerin getirdiği yüksek işlem yüküne yönelik olmuştur [13]. Son yıllarda hızlandırılmışparalelleştirilmiş filtre yapıları çokça sunulmaya başlanmıştır [14]. SLAM tahmin yöntemleri çevre ve araç tipine göre farklılık göstermekle birlikte ilk SLAM çalışmaları daha az boyut içeren, daha az kompleks kara araçları ve sonra insansı robotlarda gerçekleştirilmiştir [15]. Daha sonra gelişmiş filtre yapısı nedeniyle daha az hata üreten yaklaşımlar deniz ve hava platformlarına da uygulanmıştır [16, 17]. Oğuz ve Temeltaş [18], İHA'lar için genişletilmiş Kalman filtresi (GKF) tabanlı SLAM yapısını oluşturmuş, ilk kez A-SLAM filtredeki tutarsızlık problemini istatistik ve benzetim sonuçları ile ortaya koymuş ve filtre yapısından kaynaklanan tutarsızlık probleminin çözümünü tartışmaya açmışlardır. Belirsizlik ortamlarında durum tahmininde kullanılan filtre gözlenebilirliği, kararlılığ1 ve tutarlılığı diğer araştırma konuları olarak göze çarpmaktadır [19, 20]. Julier ve Uhlman [21] robot ve işaretçi konumlarının tekrarlı ölçülmesi ile tahmini robot konum hatasının küçüldüğünü görmüş, Castellanos vd. [22] Kalman tabanlı SLAM yöntemlerinde filtrenin lineerleştirme hatalarından dolayı tutarsızlaştığını ortaya koymuş, Huang ve Disanayake [23] ise tutarlı bir tahmin için filtre jakobiyeninin full rank olması gerektiğini gözlemlemişlerdir. Huang vd. [24] ayrıca kara araçları için oluşturulan genişletilmiş Kalman filtresi tabanlı SLAM yapısının tutarlılığını artırmak için gözlenemeyen alt uzayların filtre üzerindeki bozucu etkisini azaltmak amacıyla lagrange polinomları yöntemi ile jakobiyen matrisleri optimize etmiş ve gözlenebilirliği kısıtlanarak tutarlılığ artırılmış SLAM yapısı oluşturmuşlardır. İnsansız araçlarda konum belirlemek için kamera, lazer, ultrasonik, RADAR, LIDAR gibi farklı algılayıcı tipleri kullanılmakta olup Hesch vd. [25] mini İHA için oluşturulan SLAM yapısında kamera ve Inertial Navigation System (INS) verisi kullanmıştır. 
Yang [26] robotlar için Parçacık Filtre tabanlı SLAM mimarisini ultrasonik algılayıcı kullanarak tasarlamış ayrıca harita oluşturma sırasında dört işaretçi nesneli harita doğrulama tekniği önermiş ve algoritmanın doğruluğunun arttığını ve matematiksel işlem yükünün azaldığını sonuçlarla ortaya koymuştur. Literatürde ayrıca alt haritalama ve döngü kapama problemleri üzerindeki çalıșmalara da rastlamak mümkündür [27]. Gerçek zamanlı EZKH araştırmaları içerisinde, Thrun vd. [28] tarafından deneysel bir çalışma gerçekleştirmiş ve bu kapsamda insansı robot için gerçek zamanlı üç boyutlu konumlandırma çalışmaları da yer almıştır [29].

Yine son yıllarda çoklu araç ve sistemlerin navigasyonu üzerinde EZKH çalışmaları da sunulmuştur [30]. Bununla beraber bu sistemlerden bazıları formasyon denilen kooperatif (işbirlikçi) görev icrasını amaçlamışlardır [31]. Yıllar içinde önemli ölçüde artan Eş Zamanlı Konumlama ve Haritalama araştırmalarında ortaya çıkan yöntemlerin performanslarını tarayan ya da bu yöntemleri karşılaştıran çalışmalar da son yıllarda görülmeye başlamıştır [32]. Cadena vd. [33], geçmiş çalışmalar kadar gelecekteki potansiyel EZKH çalışmalarına da projeksiyonda bulunmuşlardır [34]. Bunlardan Huang vd. [35], başlangıçtan günümüze EZKH çalışmaları üzerine tarama ve analizler yapmış, Monjazeb vd. [36] ise EKF ve Fast SLAM performanslarını karşılaştırmış, Rigatos [37] da otonom navigasyonda Kalman filtresi ve parçacık filtresi (PF) yaklaşımlarını teknik ve maliyet etkinlik açısından karşılaştırmıştır. Parçacık akış filtresi yaklaşımı (PAF) ise ilk olarak Daum-Huang tarafından ortaya konulmuştur [38].

Ding ve Coates [39] bu yaklaşımın uygulamasını yaparken, Jilkov vd. [40] paralel çalıştırılan parçacık filtresi ile parçacık akış filtresi performanslarını karşılaştırmışlardır [41]. Ancak parçacık akış filtre yapısının EZKH problemine uyarlanması henüz literatürde görülmemiş olup bu çalışma bir ilk niteliğinde olacaktır. Ayrıca bu kapsamda incelenen parçacık akış tabanlı filtre yapısının hem diğer filtreleme çalışmalarıyla karşılaştırılarak bunlara alternatif olabilmesi hem de bu yolla konum belirleme ve haritalama problemlerinde süzücü (smoother) olarak kullanabilmesi konusunda fikir vereceği değerlendirmektedir [42, 43].

\subsection{Filtre Tabanlı EZKH Yapılarl \\ (Filter Based SLAM Structures)}

Şekil 1'de verildiği gibi belirsizlik altında tahminde bulunma yaklaşımlarının temelinde hem ölçüm (gözlem) hem de hareket (proses) belirsizliklerinden ortaya çıkan hataları indirgeme düşüncesi vardır. Bununla birlikte filtre yapısı kullanarak tahmin yapan konum belirleme ve haritalama yaklaşımları beş temel adımda ele alınabilir: Durum (Değişkenleri) Tahmini, İşaretçi Belirlenmesi, Veri (Data) Birleştirme, Durum Güncelleme ve İşaretçi Güncelleme.

Durum (Değişkenleri) Tahmini: Ĕ̆er araca ait kinematik ya da dinamik model elimizde bulunuyorsa herhangi bir anda araca uygulanacak hareket komutuna bağlı aracın bir sonraki konumunu biliniyor kabul edilir. Ancak gerçekleşen durumun algılayıcı ve ölçüm belirsizlikleri nedeniyle bundan farklı olabileceği açıktır.

Işsaretçi Belirlenmesi: Tahminden sonraki adımda alınan algılayıcı ölçümü vasıtasıyla (tekrar tanınabilir) işaretçilerinin ne olacağına karar verilir. İşaretçi belirlenmesindeki hataların aracı yanlış kılavuzlaması söz konusu olduğundan aracın tamamen kaybolması sonucu bile ortaya çıkabilir.

Veri (Data) Birleştirme: Etraftaki tüm işaretçilerin ilk belirlenmesinden sonra araç bir sonraki adım için yeni gördüğü işaretçileri eskisi ile karşılaştırmak zorundadır. Araç önce işaretçilerin aynı işaretçi olup olmadığına sonra da tahmin edilen yerlerinde olup olmadığına bakar. Tahmin edilen yerdeki farkl1lık inovasyon (yenileme) hatası olarak ortaya çıkar ve düzeltme hesaplarının içinde önemli bir paramatre olarak yer alır. Kapalı bir çevrimde dolaşan araç başladığı noktaya yeniden geldiğini anlayamaz ise hatalı bir harita ve rota oluşturur. Veri ilişkilendirmenin doğru yapılamaması yani yanlış veri ilişkilendirme aracın büyük konum hataları yapmasına sebep olacak ve bu durumda EZKH filtresinin yanlış çalışmasına yol açacaktır.

Durum Güncelleme: Araç, Durum (Değişkenleri) Tahmini adımındaki tahmini güncellemek için algılayıcıdan gelen ölçüm verisini kullanır. Kalman yaklaşımlarında bunun için inovasyon (yenileme) hatası ve Kalman kazancı denilen

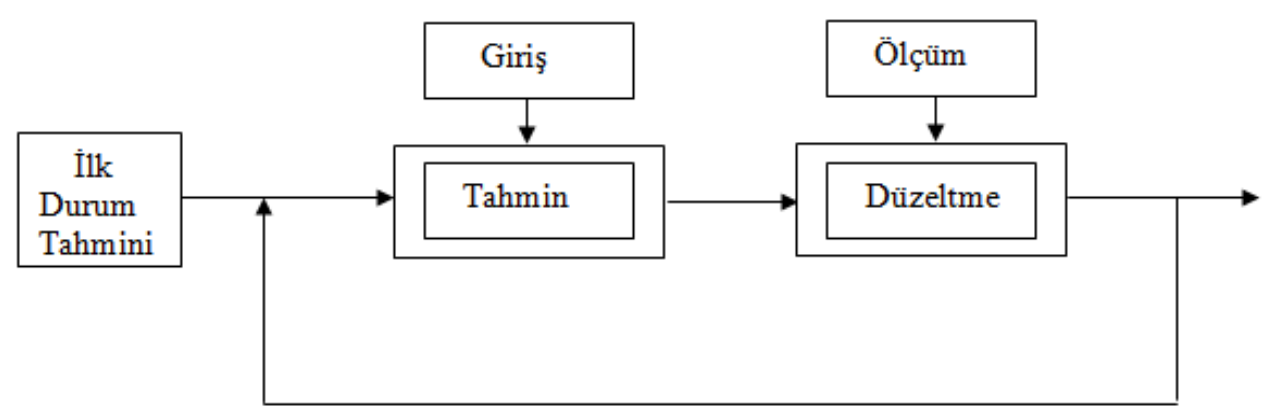

Şekil 1. Filtre tabanlı EZKH yaklaşımlarında temel adımlar (Main steps of filter based SLAM approaches) 
adımlar parçacık tabanlı yaklaşımlarda ise örnekleme ve akış belirleme gibi basamaklar işlenir. Böylece bir sonraki zaman dilimine (sonraki adıma) geçmeden tahmin düzeltilerek en iyi tahmin yapılmış olur.

Işaretçi Güncelleme: Bu adımda yeni işaretçiler alınarak genel yaklaşım devam ettirilir.

\subsection{Araç Modeli (Vehicle/Robot Model)}

Araç modeli EZKH problemi için önem teşkil etmekte olup burada diferansiyel sürücü sistemli mobil iki tekerlekli bir robot kullanılmış ve denklemleri araç kinamatiği açısından ele alınmıştır. Aracın konumu Şekil 2'de gösterildiği gibi robot üzerinde hareket merkezi ve platform ağırlı merkezi aynı noktada olan bir düzlemde 3 serbestlik dereceli $(\mathrm{x}, \mathrm{y}, \theta)$ koordinatları ile tanımlanır [44]. Açısal (dönüş) hızı $\omega$ ve her iki yönde doğrusal hızları veya teğetsel hızları Vx, Vy olarak tanımlanabilir. Birbirine bağlı olan araç tekerlekleri diferansiyel sürücü robot hareketine katkıda bulunmakla birlikte robot geometrisi ile beraber hareket kısıtlamalarını tayin ederler. Burada robota ait kontrol girdisi anlık hız (V) ve tekerleğe uygulanan anlık dönme açısı $(\varphi)$ olup araç modeli doğrusal ve difransiyel denklemler tarafindan belirlenen konum ve yönelim bilgisi içermektedir. Bu çalışmada kullanılan hareket denklemleri ise kartezyen sistemdeki iki tekerli bir araç için Eş. 1'deki gibi olsun.

$$
\left[\begin{array}{l}
x(t+1) \\
y(t+1) \\
\theta(t+1)
\end{array}\right]=\left[\begin{array}{l}
x(t)+V(t) \Delta t \cos \theta(t) \\
y(t)+V(t) \Delta t \sin \theta(t) \\
\theta(t)+V(t) \Delta t \tan \phi(t) / R
\end{array}\right]
$$

\subsection{Algllayıcı Modeli (Sensor Model)}

Genel olarak otonom araçlar üzerinde işaretçi nesnelerin tespitinde kullanılan algılayıc1lar LIDAR, RADAR, ultrasonik ya da kameradır. Algılayıcılarda işaretçi nesnelerin konumunun tespitinde görüntü işleme teknikleri de kullanılabilmekte olup bu çalışmada aracın o anki konumuna göre görüntü alanının içine giren işaretçi nesnelerin konumlarını uzaklık (x-range, y-range) olarak belirleyen ve üzerine gürültü ekleyerek gerçek duruma yaklaştırmaya çalışan bir kod dizisi ile algılayıcı modeli oluşturulmuştur.

$\left[\begin{array}{l}x(t+1) \\ y(t+1)\end{array}\right]=\left[\begin{array}{l}x(t) \sin \theta(t)-y(t) \cos \theta(t) \\ y(t) \sin \theta(t)-x(t) \cos \theta(t)\end{array}\right]$

$\mathrm{Bu}$ şekilde EZKH uygulamasında kullanılacak z(k) gözlem modeline uygun veri setleri elde edilmiştir. Algılayııı modelinin blok gösterimi ise Şekil 3'de verilmiştir. Araştırma süresince kullanılan ölçüm denklemleri yukarıda Eş. 2'de verildiği gibidir.
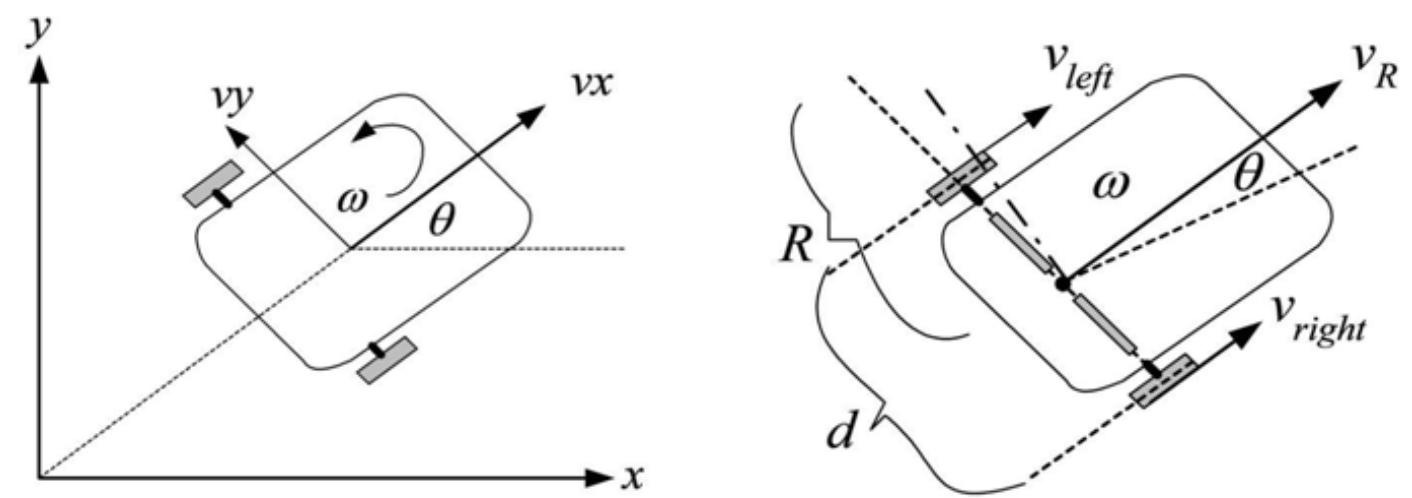

Şekil 2. Robot yapıs1 ve ilgili parametreler (Robot structure and related parameters $-\mathrm{V}_{\text {rightleft }}=$ radiuswheel $* \omega_{\text {right/lett }}$

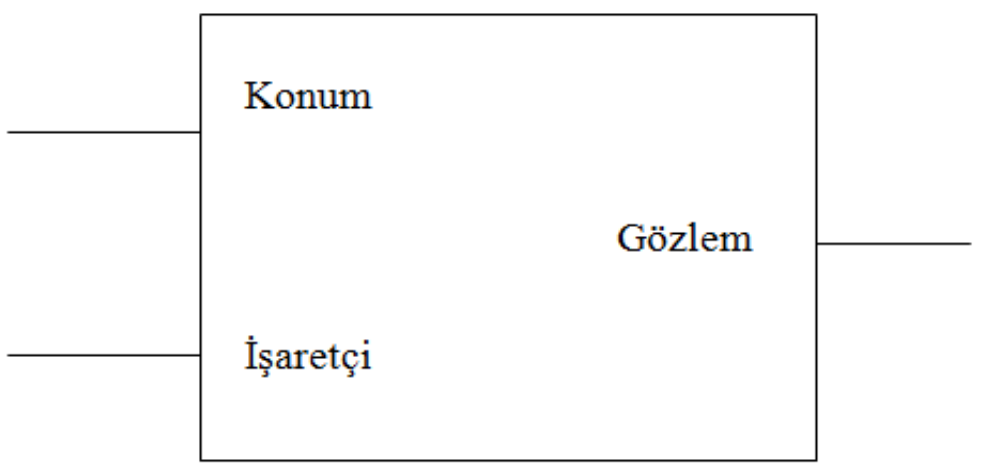

Şekil 3. Algılayıcı modeli blok gösterimi (Sensor model block diagram) 


\subsection{Entegre Sistem Benzetimi (System Simulation)}

Benzetimlerde kullanılan genel yapı Şekil 4'de gösterilmiş olup robot modeli, kontrol ve algilayıcı ile zamanda örnekleme blokları birleşik bir yapı içerisinde verilmiştir. Araç bloğunun temsil ettiği alt bileşenler ise Şekil 5'de verildiği gibidir. Burada araç girdi olarak bir komut dizisi ve alana yerleştirilmiş işaretçi nesnelerin seyrüsefer (navigasyon) düzlemi konumlarını içeren harita verisini almaktadır. Girdi verisi olarak mevcut harita ve kontrol bilgisi içeren $[\mathrm{V} ; \varphi]$ ile çıkış verisi olarak algılayıcı çıktısını içeren $\mathrm{z}(\mathrm{k})=\left[\mathrm{x}_{\mathrm{LM}} ; \mathrm{y}_{\mathrm{LM}}\right]$ ifadelerinden söz etmek mümkündür. Çıkış verisi 0.01 sn aralıklı olarak örneklenerek EZKH yapısında kullanılmaktadır. Üretilen konum verisi algılayıc1 bloğu tarafından işlenerek EZKH yapısında kullanılacak veri seti ile EZKH tarafından hesaplanan konumun gerçek konum ile farkının hesaplanmasında kullanılacak gerçek konum verisi üretilmektedir. Kamera/Laser algılayıcısı ile EZKH yapısında kullanılacak işaretçi nesne konumlarının gerçek zamanlı olarak tespiti yapılmakta ve bu amaçla veri seti üretilmektedir. Diğer çalışmalarda bir yer aracının sözkonusu yörüngede dolaştırılmasıyla toplanmış gerçek verinin işlenmesi de mümkün olacaktır.

\subsection{Uygulama Benzetimi - Senaryo (Simulation Scenario)}

Entegre benzetim senaryosunda sabit hızda hareket eden araç Şekil 6'da verildiği gibi tam bir döngü oluşturacak biçimde 10 metrelik dairesel bir alanda dolaşmaktadır. Çalışmanın esas amacı EZKH ile konum ve haritanın belirlenmesi problemi için belirsizlik altında yeni bir tahmin yöntemi olarak parçacık akış filtresi performanısını değerlendirmek

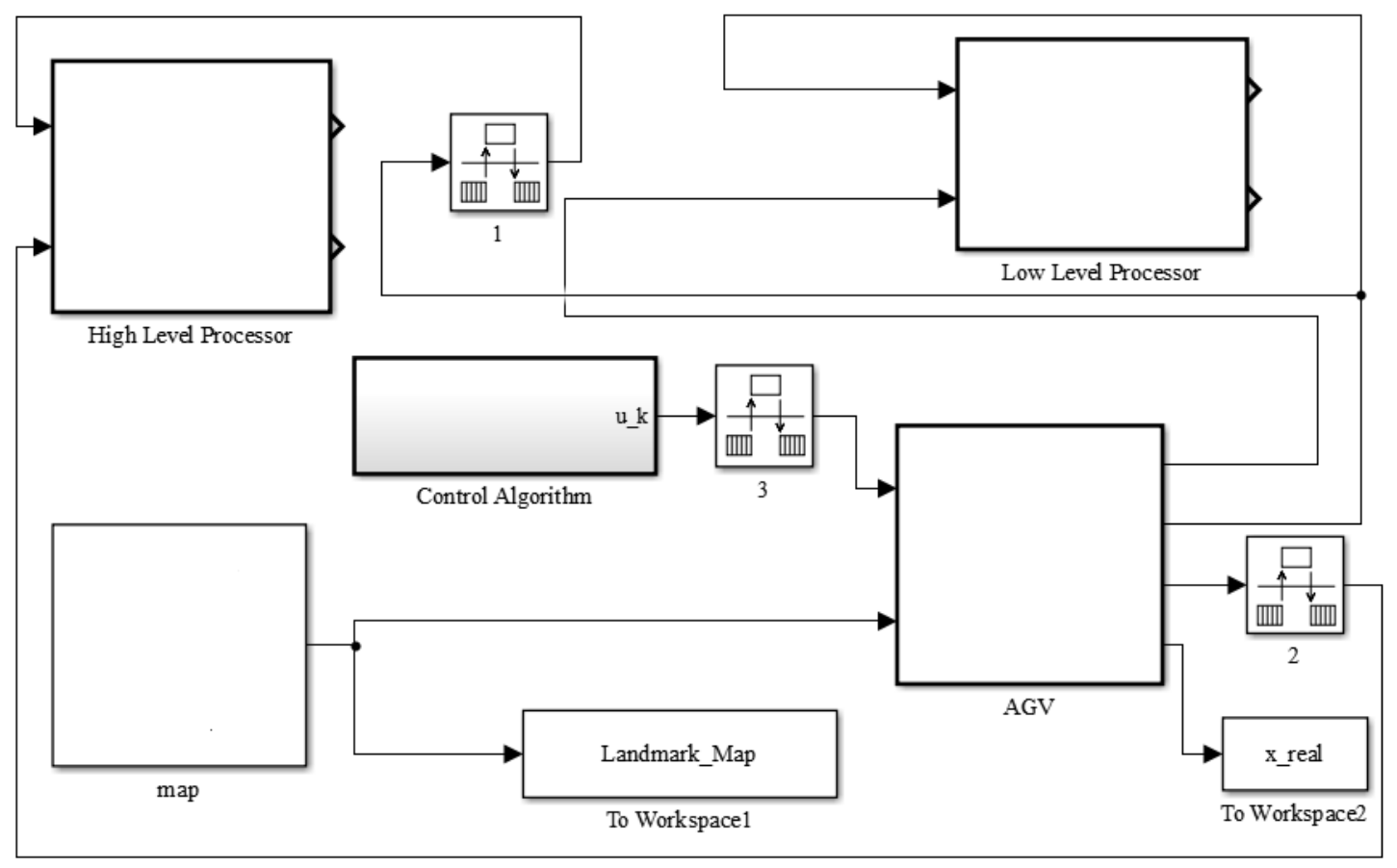

Şekil 4. Benzetim yapısı (Simulation model - Block diagram)

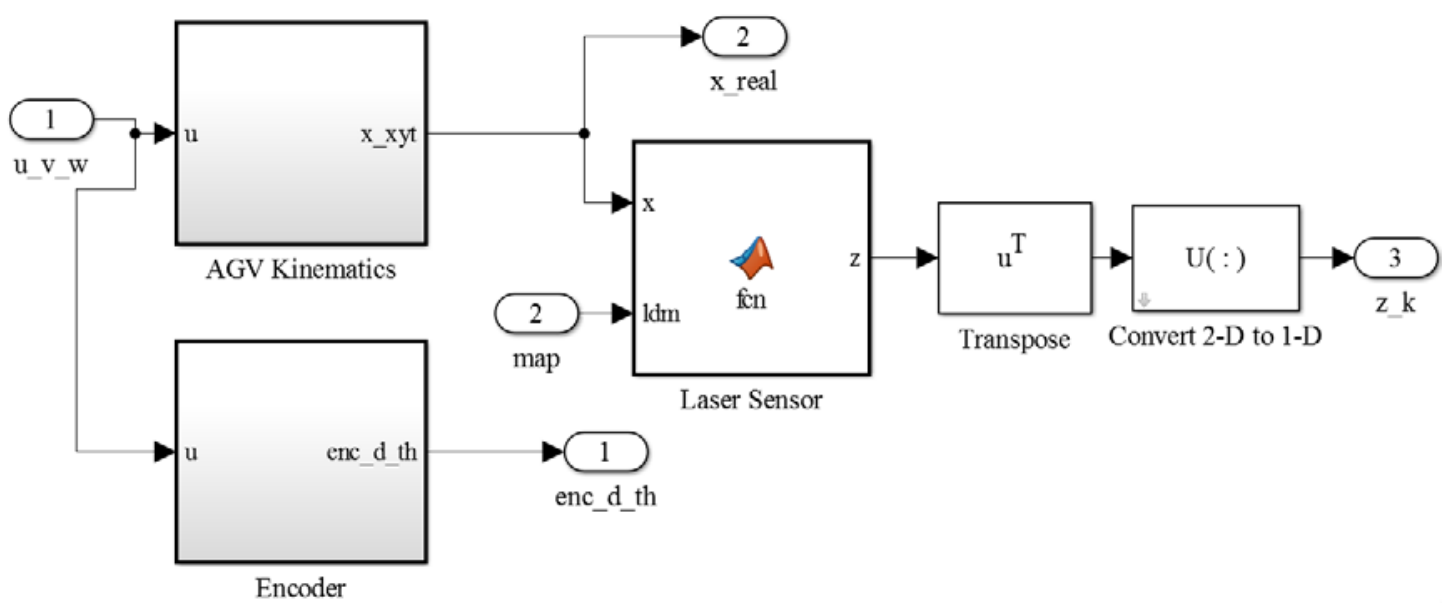

Şekil 5. Araç modeli blok gösterimi (Robot model block diagram) 


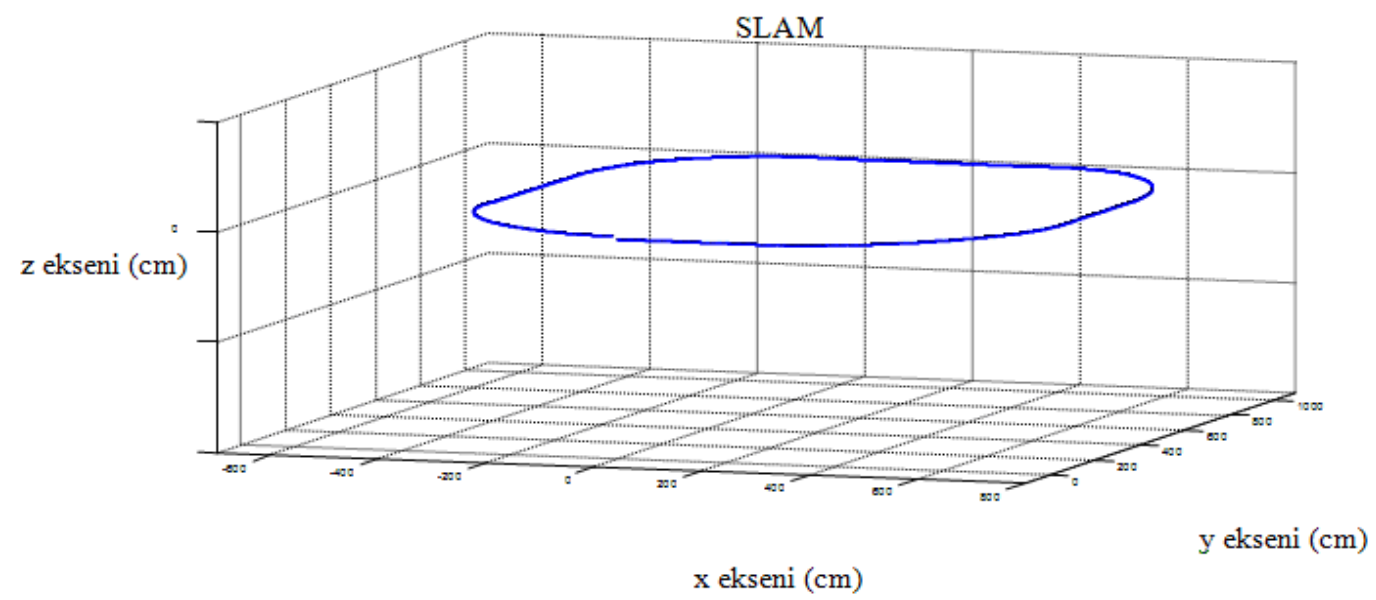

Şekil 6. İnsansız aracın yol güzergahı (Autonomous unmanned vehicle - AUV path trajectory)

olduğundan ortam koşulları için öncelikle en sade durumlar göz önüne alınmıştır. Bu kapsamda aracın seyahat süresince herhangi bir engelle karşılaşmadığı, güzergah boyunca birbirinden yeterli uzaklıkta gördüğü belirli sayıda işaretçiyi doğru bir şekilde tanımlayarak bir döngü kapama gerçekleştirdiği kabul edilmiştir. Araştırma süresince algılayıcı ile işaretçi nesne algılaması ve EZKH ile konum ve haritanın belirlenmesi hedeflenmiş olup sistemin çalışması benzetimler sırasında farklı ölçüm ve sistem (hareket ya da araç) belirsizlikleri ile denemeler yapılarak incelenmiştir. Bölüm 4'te verilen grafikler ise $\% 1$ encoder ve \%10 lazer algılayıcı belirsizlikleri koşullarında elde edilmiştir.

\section{TEORIK METOD (THEORETICAL METHOD)}

Parçacık akış filtresi yapısında paralel işleyen Kalman yapısı bulunması ve genel değerlendirme bölümünde performans karşılaştırması verileceğinden EZKH probleminde belirsizlik altındaki tahmin yaklaşımlarını ve bunları oluşturan adımları kısaca irdelemede fayda görüyoruz.

\subsection{Kalman Filtresi Tabanl EZKH Yapılar (Kalman Filter Based SLAM Structures)}

Kalman tabanlı filtreler beklendiği gibi kullanılan sisteme ait durum uzay (state space) modeline ihtiyaç duyarlar. Bu model hem araç ya da platform için hareket modelini (motion model) hem de algılayıcılar için gözlem modelini (observation model) gerektirir. Her iki model kullanılarak yapılan durum ve gözlem tahminlerinden sonra güncelleme (update) adımında gözlem tahmin hatası (inovasyon) ve Kalman kazancı kullanılarak durum (state) güncellemesi tamamlanır. Lineer durum uzayı ile modellenen sistemlerde önceki durum ve ölçüm değerine göre sonraki durumu tahmin eden filtre yapısı için durum uzay modeli ve ölçüm değeri ise Eş. 3'deki gibi olsun.

$x(k+1)=A x(k)+B u(k)+v(k)$
$z(k)=H x(k)+\omega(k)$
Durum uzay modeli ve ölçüm değerinde, A, B, H araç modeline göre sırasıyla durum, giriş ve gözlem matrislerini; $\mathrm{x}(\mathrm{k})$ durum uzayını; $\mathrm{u}(\mathrm{k})$ giriş ve $\mathrm{z}(\mathrm{k})$ gözlem verilerini; $\mathrm{v}(\mathrm{k})$ Q kovaryanslı proses gürültüsünü; $\omega(\mathrm{k})$ ise $\mathrm{R}$ kovaryanslı ölçüm gürültüsünü göstermektedir.

Lineer olmayan sistem modelinde kullanılan durum vektörü Eş. 4'deki gibi araç durum vektörü ile harita vektöründen oluşur. Kara aracı durum vektörünü konum (x, y) ve yönelim açısı $(\theta)$ oluşturulmuștur. Harita vektörü ise, her işaretçi nesneye ait konum $\left(\mathrm{x}_{\mathrm{L}}, \mathrm{y}_{\mathrm{L}}\right)$ bilgilerinden oluşmaktadır. $\mathrm{Bu}$ vektörün uzunluğu 2xn (n:işaretçi nesne sayısı) olur [18].

$x(k)=\left[\begin{array}{l}x_{A G V} \\ x_{M A P}\end{array}\right]$

Genişletilmiş Kalman filtresi lineer durum uzayı ile modellenen sistemlerde önceki durum ve ölçüm değerine göre sonraki durumu tahmin eden filtre yapısıdır. Kalman filtresinde olduğu gibi tahmin ve düzeltme adımlarından oluşur. Filtrede kullanılacak durum uzay modeli Eş. 5'deki gibi ifade edilir.

$x(k+1)=f(x(k), u(k), v(k))$

Durum uzay modelinde $\mathrm{k}+1$ anındaki durum vektörü $\mathrm{k}$ anındaki durum vektörü ve giriş verisine bağlı olarak bulunur. İşaretçi nesne konumu gözlem modelinde gösterildiği gibi uzaklık ve açı olarak polar koordinatlarda bulunur. Algılayıc1 düzleminden koordinat düzlemine dönüşümü Transformasyon matrisleri kullanılarak yapılır. Gözlem modeli aracın k anındaki konum bilgilerine bağlıdır ve Eş. 6'daki gibi ifade edilir [18].

$z(k)=h(x(k), \omega(k))$

Burada $\mathrm{v}(\mathrm{k})$ ve $\mathrm{w}(\mathrm{k})$ sıfır ortalamalı beyaz gürültüdür ve durum uzay modelinin konum ve açıdan oluştuğu görülecektir. Durum uzay modeli araç kinematik 
denkleminden elde edilmiştir. Gözlenen işaretçi nesnenin haritada olup olmadığını anlamak için Euclid yerine Mahallanobis uzaklığına bakılabilir. Bu uzaklık belirli bir limitin altında ise haritada yer alanlardan en küçük uzaklığa sahip olan veri ile ilişkilendirilir. EZKH filtresi güncelleme adımında ilişskilendirilen veriler arasındaki farkı kullanır. Julier ve Uhlmann tarafindan ortaya konulan dağıtılmış Kalman filtresi (DKF) yapısı ise genişletilmiş Kalman filtresi gibi yine tahmin ve düzeltme adımlarından oluşan Kalman filtresi yapısıdır. İki filtre arasındaki temel fark GKF'de lineer olmayan sistemin lineerleştirilmesi için türev yolu ile elde edilen jakobiyen matrislere ihtiyaç duyulurken DKF'de ise jakobiyen matrislere ihtiyaç duyulmaz. DKF yapısı temel olarak belirsizlik sınırlarının yani normal dağılımdaki kovaryansların bir önceki araç konumuna eklenip çıkarılmasıyla $2 n+1$ noktanın elde edilerek bu noktalar için sistem modelinin çalıştırılması ile elde edilen sonuçların belirli bir ağırlıkla ortalamasının alınması ve bir sonraki adımın tahmin edilmesi ve aynı şekilde gözlem modelinin çalıştırılması ile elde edilen sonuçların belirli bir ağırlıkla ortalamasının alınması ile tahminin düzeltilmesi olarak açıklanabilir.

Lineer olmayan sistemin ve gözlem modeli birinci ve ikinci momentleri (ortalama ve varyans) Eş. 7'deki gibi şöyle yazilır.

$$
\begin{aligned}
& \bar{x}=E[x], \sum_{x}\left[(x-\bar{x})(x-\bar{x})^{T}\right] \\
& \bar{z}=E[z], \sum_{x}\left[(z-\bar{z})(z-\bar{z})^{T}\right]
\end{aligned}
$$

Her durum değişkeni için 2n+1 (n:Durum uzay modeli boyutu) sigma noktası $\left(\mathrm{X}^{\mathrm{k}}\right)$ seçilir. Sigma noktaları Eş. 8 'deki gibidir. Burada $\lambda$ orantı faktörüdür [18].

$\chi^{0}=\bar{x}$

$\chi^{k}=\bar{x} \pm\left[\sqrt{(n+\lambda) \sum_{x}}\right]_{k} \quad k=1, \ldots, n$

Sigma noktaları için ağırlık katsayısı Eş. 9'daki gibi olur.

$$
\begin{aligned}
& W_{0}=\frac{\lambda}{n+\lambda} \\
& W_{k}=\frac{\lambda}{2(n+\lambda)} \quad 0<k \leq 2 n
\end{aligned}
$$

Kovaryans matrisi için ağirlık katsayısı Eş. 10'daki gibi hesaplanır [18].

$$
\begin{aligned}
& W_{0}=\frac{\lambda}{n+\lambda}+1-\alpha^{2}+\beta \\
& W_{k}=\frac{\lambda}{2(n+\lambda)} \quad 1<k \leq 2 n
\end{aligned}
$$

$\mathrm{Bu}$ işlem sonrasında aracının bir önceki konum ve giriş değerlerine göre bir sonraki konumun tahmini yapılır. Tahmin adımı olarak adlandırılan bu adımda bir önceki konumdan elde edilen $2 n+1$ sigma noktalarına göre bir sonraki ana ait durum tahminleri, hesaplanan durum tahminlerinin ortalaması ve bu durum tahminleri kullanılarak yapılan kovaryans tahmini (sırasıyla) Eş. 11 'deki gibidir [18].

$$
\begin{aligned}
& \chi^{k}(t+1 \mid t)=f\left(\chi^{k}(t \mid t), u(t)\right) \\
& \hat{x}(t+1 \mid t)=\sum_{i=1}^{2 n+1} W_{i} \chi^{i}(t+1 \mid t) \\
& P(t+1 \mid t)=\sum_{i=1}^{2 n+1} W_{i}\left[\left(\chi^{i}(t+1 \mid t)-\right.\right. \\
& \left.\hat{x}(t+1 \mid t)) \cdot\left(\chi^{i}(t+1 \mid t)-\hat{x}(t+1 \mid t)\right)^{T}\right]
\end{aligned}
$$

Gözlem tahminleri ve ağırlık katsayıları kullanarak bulunan gözlem tahmini ortalaması Eş. 12'deki gibidir.

$$
\begin{aligned}
& Z_{i}(t+1 \mid t)=h\left(\chi^{i}(t+1 \mid t)\right) \\
& \hat{z}(t+1 \mid t)=\sum_{i=1}^{2 n+1} W_{i} Z_{i}(t+1 \mid t)
\end{aligned}
$$

İnovasyon (ölçüm) kovaryansı ile korelasyon matrisi ise Eş. 13'deki gibi hesaplanır.

$$
\begin{aligned}
& S(t+1 \mid t)=\sum_{i=1}^{2 n+1} W_{i}\left[\left(Z_{i}(t+1 \mid t)-\right.\right. \\
& \hat{z}(t+1 \mid t)) \cdot\left(Z_{i}(t+1 \mid t)-\hat{z}(t+1 \mid t)\right)^{T} \\
& P_{x, z}(t+1 \mid t)=\sum_{i=1}^{2 n+1} W_{i}\left[\left(\chi^{i}(t+1 \mid t)-\right.\right. \\
& \hat{x}(t+1 \mid t)) \cdot\left(Z_{i}(t+1 \mid t)-\hat{z}(t+1 \mid t)\right)^{T}
\end{aligned}
$$

Güncelleme adımında, tahmin adımında elde edilen sonuçlar ölçüm ile elde edilen korelasyon ve inovasyon matrisleri kullanılarak güncellenir. Güncelleme adımında korelasyon matrisine göre Kalman kazanc1, durum güncellemesi ve güncellenmiş kovaryans değerleri Eş. 14'deki gibi bulunur [18].

$$
\begin{aligned}
& K(t)=P_{x, z}(t+1 \mid t) \cdot P_{x, z}(t+1 \mid t)^{T} \\
& \hat{x}(t+1 \mid t+1)=\hat{x}(t+1 \mid t)-K(t)(z(t)-\hat{z}(t+1 \mid t)) \\
& P(t+1 \mid t+1)=P(t+1 \mid t)-K(t) S(t+1 \mid t) K^{T}(t)
\end{aligned}
$$

Böylece bir önceki konum ve giriş değerleri ile ölçüm kullanılarak bir sonraki konu hesaplanmış olur ve çevrim bu şekilde devam eder. Bilindiği üzere EZKH problemi üzerine yapılan çalışmalarda, filtre tarafindan yapılan hesaplama hatasının azaltılması ve bu amaçla filtre tutarlılı̆̆ının artırılması hedeflenmektedir. Kara, deniz ve hava platformu araçlarının dinamik ve kinematik denklemleri lineer olmadığından EZKH yapısında lineer olmayan sistemlere uygulanan genişletilmiş Kalman filtresi ve dağılımlı Kalman filtresi kullanılmaktadır. Genel olarak yakınsamaları daha iyi olmakla birlikte genişletilmiş Kalman filtresi birinci türevlerden oluşturulan jakobiyen matrisler yoluyla 
lineerleştirme yaptığından türev hatası oluşturmakta ve bu durum da EZKH yapısında tahmin hatası nedeni olarak ortaya çıkmaktadır.

\subsection{Parçacık Filtresi (PF) Tabanlı EZKH Yapısı (Particle Filter Based SLAM Structures)}

Parçacık Filtresi ise yine durum tahmininde başvurulan bir yöntem olup başlangıç durumu (state) için Gauss dağılmış herhangi bir değişken kullanır. Dağılımdaki her örneklenmiş değer bir parçacık olarak görev yapar. Aracın kinematik modelini kullanarak yapılan tahmin tüm parçacıklar için yinelenir. Gözlem sonuçlarına bakarak hangi parçacığın hangi ağırlıkta olacağı hesaplanır. Gözleme yakın tahminlerin ağırlığı fazla olacaktır.

Ağırlık hesaplanmasından sonra yeniden örnekleme (resampling) işlemine geçilir. $\mathrm{Bu}$ aşamada mevcut dağılımdaki örneklere ait kümülatif toplam kulanılarak yeni bir parçacık dağılım elde edilir. $\mathrm{Bu}$ dağılımda önceki örnekler içinden ağırlığı yüksek olanlar daha fazla yer alacaktır. Bu durumda bazı parçacıklar yok olurken bazı parçacıkların iterasyonlara daha güçlü devam etmesi (surviving of the fittest) beklenmektedir. Parçacık filtresi adımları örnekleme, önem ağırlıklarının hesaplanması, yeniden örnekleme olarak özetlenebilir.

\section{PARÇACIK AKIŞ FILTRESİ TABANLI TABANLI EZKH \\ (PARTICLE FLOW FILTER BASED SLAM)}

Eş zamanlı konum belirleme ve haritalamada bir süredir devam edegelen çalışmalara rağmen çok boyutlu non-linear sistemlerin belirsizlik altında tahmin ve filtrelemesi çözülmesi beklenen önemli problemlerdendir. EZKH problemlerinde temel olarak aracın dinamik/kinematik modeline bağlı olarak yapılan tahmin ve araç üzerindeki algıyacılardan alınan gözlem bilgisi kullanılarak yapılan güncellemeden bahsedilmiş idi. Birbiri ardına işleyen bu adımların iterasyonu ile aracın en doğru konum ve harita bilgisine ulaşılması amaçlanmaktadır. Bu kapsamda Daum ve Huang belirsizlik altında daha hızlı ve doğru tahmin için farklı bir non-linear filtreleme teorik yaklaşımı ortaya koymuş ve parçacık akış filtresi ismiyle birden fazla versiyonu içeren ilk çalışmalarını yayımlamışlardır. [38]

\subsection{Parçacık Akış Filtresi (Particle Flow Filter-PFF)}

Parçacık akış filtresi belirsizlik altında tahmin imkanı sağlayan parametrik olan ve olmayan diğer filtreler gibi sistem modeli üzerinden yapılan tahminde en az hatalı değerleri üretmek iddiası ile ortaya çıkmıştır. Parçacık filtresi yapısında bir iyileştirme yaparak parçacık dejenerasyonu ortadan kaldırmış ve örneğin EZKH problemi için aracın konumuna ait bilgiler taşıyan parçacıkların tanımlanan logaritmik bir homotopi fonksiyonu (homotpy function) vasıtasıyla bir sonraki adımda soncul olasılığ 1 en yüksek parçacıklara en hızlı şekilde yakınsamasını sağlamıştır.

\subsection{Parçacık Akış Filtresi Teorisi \\ (Particle Flow Filter Theory)}

Parçacıkların bu akışları için öncül (prior) ve soncul (posterior) olasılık yoğunluk dağılımları arasında geçiş tanımlayan homotopi fonksiyonu ve bu fonksiyonun adım parametresi ile durum arasında tanımlanan difransiyel denklemin (Itostochastic PDE-Partial Differential Equation) çözümünü kullanır. Parçacık akış filtresi yöntemi bu denklemin çözümünün bir Fokker-Plank yaklaşımda aranmasından bahsederken parçacıkların Fokker Plank denklemleriyle belirlenen miktarlarda soncul olasılıkları yüksek bölgelere akışlarını (migrasyon) sağlar [38].

Bir başka anlatımla parçacık filtresi yapısında, durum uzay modelinde bir state (durum) için öncül-prior olasılık uzayından başlanarak ortalaması kendisi olacak şekilde etrafında normal dağılımdan örneklenmiş $n$ adet parçacığın hareket ve gözlem modelini kullanarak tahmin adımından geçirilmesi (her bir parçacığın tahmin yapması) ve gözlem hatalarına bakılarak en yakın tahmin yapan parçacıkların daha güçlü olarak iterasyona devam etmesine dayadığından bahsedilmiş idi. Parçacık akış filtresi, burada bir iyileştirme yaparak parçacıkların tanımlanan bir homotopi fonksiyonu (homotpy function) vasitasıyla en hızlı şekilde en güçlü parçacıklara yakınsamasını sağlar. Böylelikle daha hızlı ve aynı zamanda daha doğru tahminler yapan bir algoritma ortaya koyar. Parçacık akış filtresi adımları Şekil 7'de verildiği gibidir. Sistem ve gözlem ifadeleri denklem (4) ve (5) ile verildiği gibi olsun. Hatırlanacağı üzere normalize olmayan marjinal (soncul) posterior olasılık yoğunluğunu tanımlamak üzere kullanılan Bayes kuralı Eş. 15'deki gibi şöyle idi [38]:

$p\left(x_{t} \mid y_{1: t}\right)=p\left(y_{t} \mid x_{t}\right) p\left(x_{t} \mid y_{1: t-1}\right)$

Burada Eş. 16'daki gibi sırasıyla;

$$
\begin{aligned}
& h\left(x_{t}\right)=p\left(y_{t} \mid x_{t}\right) \\
& g\left(x_{t}\right)=p\left(x_{t} \mid y_{1: t-1}\right)
\end{aligned}
$$

Gözlem ve öncül olmak üzere soncul ve öncül olasılık yoğunlukları arasındaki ilişki için tanımlanacak bir homotopy fonksiyonu Eş. 17'deki gibi şöyle olur [38]:

$\log \varphi\left(x_{t}, \lambda\right)=\log g\left(x_{t}\right)+\lambda \log h\left(x_{t}\right)$

$\lambda$ ise, 0 ve 1 arasında tanımlı ve gerçek değerli, sürekli bir parçacık akış miktarı belirleyen bir adım parametresi olsun. Burada soncul olasılık yoğunluğunun logaritması $(\lambda=0)$ iken $\log g\left(x_{t}\right)$ ve $(\lambda=1)$ iken öncül ve olabilirlik (likelihood) değerlerinin log toplamı kadar olur. Ölçüm (evidence) değeri ise normalize faktörü olarak hesaba katılmıştır. Logaritmaları eşitliğin iki tarafından da kaldırdığımızda ise son durumda öncül ve olabilirlik çarpımının Bayes kuralı gereği soncul değerine eşit olduğu görülür. 
Parçacık $\left\{x_{0}^{t}\right\}^{N}=1$ Üretilmesi ( $\mathrm{p}\left(\mathrm{x}_{0}\right)$ başlangıç dağılmm; $\hat{x}_{0}$ parçacık ortalamasi; $\mathrm{P}_{0}$ kovaryans matris)

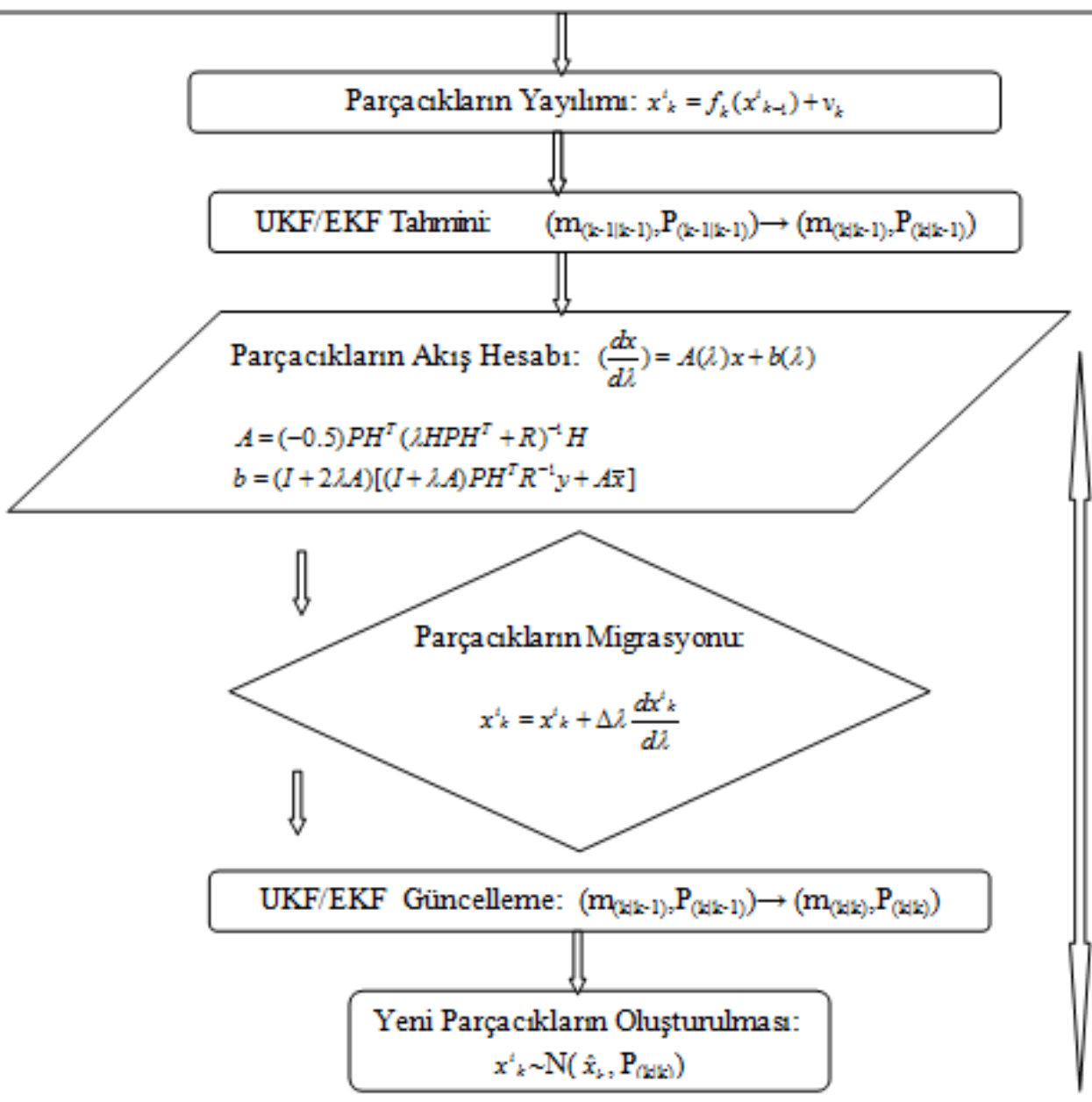

Şekil 7. (Exact) Parçacık akış filtresi tabanlı EZKH algoritması (Particle flow filter based SLAM algorithm)

$\left(\frac{\partial \phi}{\partial x} \frac{d x}{d \lambda}\right)+\frac{d \phi}{d \lambda}=0$

Yukarıdaki Eş. 18 ile verildiği gibi ito-stokastik eşitliğin ise homotopi fonksiyonundaki $\lambda$ adım değişkeni ile akış arasındaki değişimi ifade edeceği kabul edilmiştir. Bu ifadeye göre parçacıkların akışı logaritmik homotopi fonksiyonunun yönlü türevi (gradient) yönünde ve logaritmik gözlem (h) ile orantılı hızda gerçekleşerek gradientin sıfıra eşit olduğu yerde durmaktadır. Burada parçacık akışlarını belirleyen ito-stokastik eşitliğin Eş. 19'daki gibi Fokker-Planck adi difrensiyel denklemini (ordinary differential equation-ODE) kullanarak bulanabileceği varsayılmaktadır [38].

$\left(\frac{d x}{d \lambda}\right)=\psi(x, \lambda)$

Eş. 20 ile verilen denklemin çözümü ise olasılık yoğunluk akışını belirler. $\frac{\partial \varphi}{\partial x} \psi(x, \lambda)+\log (h)=-\operatorname{Tr}\left(\frac{d \psi}{d x}\right)$

Bu durumda parçacıklardaki akışın miktarına etki eden A ve $\mathrm{b}$ değerleri ile parçacıkların her iterasyondaki akış miktarları Eş. 21'deki gibi şöyle oluşur [38];

$A=(-0.5) P H^{T}\left(\lambda H P H^{T}+R\right)^{-1} H$

$b=(I+2 \lambda A)\left[(I+\lambda A) P H^{T} R^{-1} y+A \bar{x}\right]$

$\left(\frac{d x}{d \lambda}\right)=A(\lambda) x+b(\lambda)$

Burada konum bilgisi taşıyan ve her döngüde migrasyon geçiren $\mathrm{x}$ durum değişkeninin adım büyüklüğü $\lambda$ 'ya bağlı değişimi $(\mathrm{dx} / \mathrm{d} \lambda)$ durum ve parçacıklardaki akışın miktarını belirlerken, $\mathrm{A}$ ve $\mathrm{b}$ değişkenleri ise biri durum ile diğeri ise serbest olarak değişen, $\mathrm{P}$ ve $\mathrm{R}$ kovaryans değerleri ile $\mathrm{H}$ gözlem matrisine bağlı ve akış miktarının belirlenmesine neden olan iki parametredir. 


\subsection{Algoritma (Algortihm)}

Parçacık akış filtresi yapısında temel olarak öncül (prior) ve soncul (posterior) olasılık yoğunluk dağılımlarının logaritmaları arasında geçiş tanımlayan bir homotopy fonksiyonu kullanılır. Parçacık akışı (exact-particle flow) yaklaşımı ile parçacık filtresi yöntemindeki parçacık ağırlıklandırması ve önem örneklemesi içeren iterasyonlar yerine her adımda paralel koşan genişletilmiş Kalman filtresinden gelen kovaryans bilgileri kullanılarak bir sonraki adımın parçacıklarına ulaşmak amaçlanır. Bu çalışmada her ne kadar GKF tercih edilmiş olsa da genel bir yaklaşım olarak genişletilmiş yerine dağıtılmış Kalman filtresi kullanımının hatta sıkıştırılamaz (incompressible) ya da dönmez (irrotational) parçacık akış filtresi yaklaşımlarında olduğu gibi GKF/DKF olmadan farklı kovaryans hesaplarının mümkün olduğu söylenebilir [38]. Kullanılan algoritmada ise ilk olarak $\mathrm{x}_{0}$ durumundan $\mathrm{n}$ adet parçacık üretimi gerçekleştirilir. Bununla iterasyonlar Kalman tabanlı filtredeki bir state (durum) yerine $\mathrm{n}$ durumla gerçekleştirilmiş olur. Ardından $\mathrm{x}_{0}$ ve $\mathrm{m}_{0}$ ortalama; $\mathrm{P}_{0}$ ise kovaryans olarak atanır. $\mathrm{Bu}$ noktadan sonrakiler parçacık akış filtresi tahmin ve güncelleme adımlarını oluşturarak her iterasyonda yenilenecektir. Üretilen $n$ parçacık hareket modeliden geçirilir ve bu değerlerden ölçüm matrisi hesabına girecek olan $\mathrm{x}_{\mathrm{k}}$ ortalama değerleri bulunur. Öncül ve soncul olasılık dağılımları arasında tanımlanan homotopi fonksiyonu ile ortaya çıkan $\lambda$ parametresine bağlı olarak ifade edilen itostochastic differansiyel denklemin çözümü parçacıkların akış miktarlarını belirleyecektir. Şekil 7 ile verilen algoritma yapısında görüldüğü gibi parçacık akış filtresi işlem adımları içinde (kovaryans hesapları için) paralel olarak çalışır. Parçacıkların üretilmesinden hemen sonraki adımda EKF ya da UKF tahmin adımları koşulur. Tahmin edilen kovaryans değeri, gürültü kovaryansları ve gözlem matrisi ile birlikte parçacıkların akışlarının belirlenmesinde kullanılan $A$ ve $b$ değerlerinin hesaplanmasında kullanılır.

$\mathrm{Bu}$ adımlardan sonra başlangıçta üretilen parçacıklar yerine akış miktarlarının eklenmesi ile oluşan yeni parçacıklar işlemlere devam eder. UKF ya da EKF güncelleme adımları işlenir. Güncellenen parçacıkların ortalaması sonraki iterasyona girer. Algoritmanın böylelikle en hızlı ve doğru bir şekilde son duruma yakınsaması sağlanır. Farklı bir yaklaşımla parçacık akış filtresi bir sistemin durumunu izlemek için bir parçacık kümesinin zaman içerisinde yayılımını sağlar ancak bunu klasik parçacık filtresinden farklı olarak önem örneklemesi (importance sampling) ve öneri yoğunluğu (proposal density) yaklaşımlarını kullanmadan yapar. Burada parçacık akış filtresinin temel amac1; parçacık filtresinde ortaya çıkan parçacık dejenerasyonunu (particle degeneracy) engellemek, bunun için parçacık kümesini/bulutunu (particle cloud) herhangi bir öncül yoğunluktan örnekleme yapmadan hareket ettirmek, başka bir ifadeyle başlangıçta tanımlanan (log)homotopy fonksiyonunu kullanarak öncülden (prior) soncul (posterior) olasıllk yoğunluk geçişine (akışına) karşıl1k gelen bir parçacık akışı tespit etmektir [38].

\section{BULGULAR (FINDINGS)}

$\mathrm{Bu}$ bölümde daha önce teorik ve matematik olarak ortaya konulmuş olan parçacık akış filtresi tabanlı EZKH yapısının performansı farklı senaryolardaki birçok benzetim ile belirlenmeye çalışılmıştır.

\subsection{Benzetim Sonuçları (Simulation Results)}

Algoritmanın tutarlılığını belirlemek için farklı konfigürasyonlardaki bilgisayarlar kullanılarak gerçek zamanlı uygulamalarda çok önemli olan ortalama işlem süresi ile birlikte sistem parametrelerinin değişimleri ve hataların etkisi karşılaştırmalı olarak belirlenmeye çalışılmıştır. Gürültü kovaryansları, parçacık sayısı, adım büyüklüğü gibi parametrelere bağlı olan örnek bir senaryo dahilinde genişletilmiş Kalman, parçacık ve parçacık akış filtresi yapıları kullanılarak eğrisel bir güzergahta gerçekleştirilen bir eş zamanlı konum belirleme ve haritalama performansları Şekil 8'de verilmiştir. Burada aracın gerçek konumuna en yakın tahminlerin parçacık akış filtresi yöntemi ile elde edildiğini görülmektedir.

Şekil 8'de aracın gerçek konumuna en yakın tahminlerin parçacık akış filtresi yöntemi ile elde edildiği görülmekte olup benzetimler süresince elde edilen ortalama ve toplam hata metrikleri de yöntemin üstünlüğünü doğrulamaktadır. Ayrıca bir başka bakış açısından parçacık akış filtresi tahminlerinin bir kontrol algoritması şeklinde gerçek pozisyon değeri etrafında değiştiği görülmektedir. Parçacık Akış Filtresi tabanlı Eş Zamanlı Konum Belirleme ve Haritalamada araç konum ve yönelim açısı değişimi Şekil 9 ve 10'da verildiği gibidir. Parçacık Akış Filtresi tabanlı Eş Zamanlı Konum Belirleme ve Haritalamada aracın konumuna bağlı olarak türetilen hızın zamanla değişimi ise Şekil 11'de verildiği gibidir. GNSS olmadığı ortam şartları düşünüldüğünde bir kara aracı (robot) için gerçekleştirilen PAF tabanlı EZKH benzetiminde sonuçlar AGV position ve hız hatasının belli bir süre için kabul edilebilir bir seviyede kaldığını ancak uzun süren benzetimler gerçeklendiğinde ise biriken hata nedeniyle $2 \sigma$ güvenilirlik sınırlarından uzaklaşılabildiğini göstermiştir.

Parçacık Akış Filtresi tabanlı Eş Zamanlı Konum Belirleme ve Haritalamada aracin Y ekseni konumunun tahmininde ortaya çıkan hata Şekil 12'de verildiği gibidir. Şekilde Y değişkeni (ekseni) aracın düzlemde y koordinatını temsil etmekte olup mavi çizgiler hata miktarını kırmızı çizgiler ise güvenirlik aralığını temsil etmektedir. Parçacık akış filtresinde güncelleme adımı içinde yer alan parçacıkların migrasyon miktarlarının filtrenin tahmin performansına etkisinin belirlenmesi adına tekrarlı benzetimlerle belirlenmeye çalışılan akış adım büyüklüğünün değişim etkisi ise Şekil 13'de verildiği gibi olup adım büyüklügünün 50'den küçük olduğu değerlerde hatanın daha az oluştuğunu söylemek mümkündür. Adım büyüklügünün artmasının tahmin hatası üzerinde azaltıcı etkisi olmadı̆̆ gibi işlem yükünü arttıracağı şüphesizdir. 
Duymaz ve ark. / Journal of the Faculty of Engineering and Architecture of Gazi University 32:4 (2017) 1255-1270

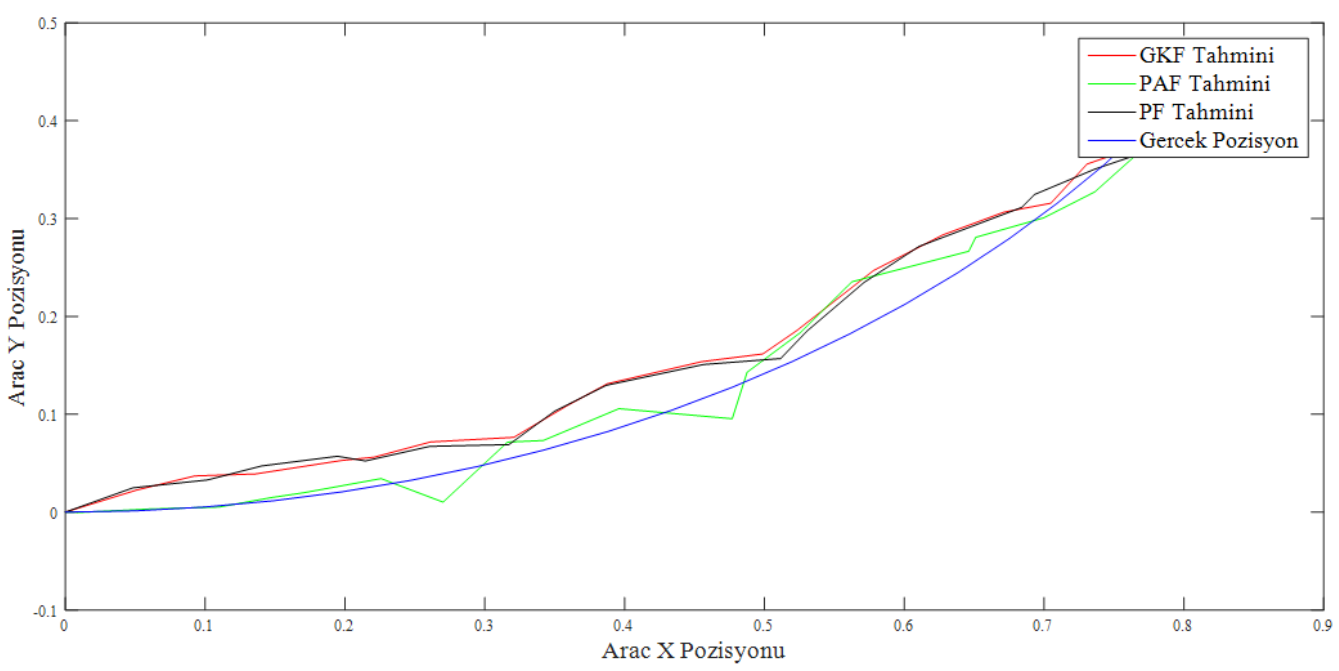

Şekil 8. PAF tabanlı EZKH performansı ve karşılaştırmalar (Particle flow filter based SLAM performance comparison)
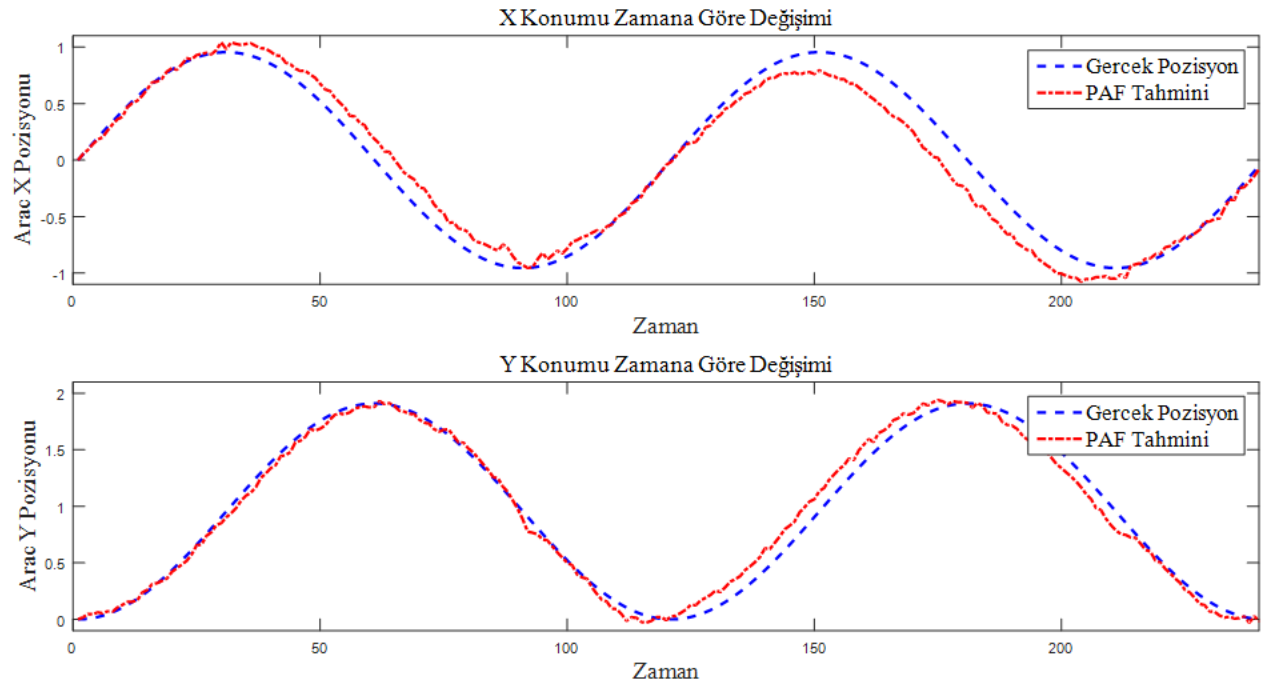

Şekil 9. Parçacık akış filtresi tabanlı EZKH araç konum değişimi (Particle flow filter based SLAM - Displacement)

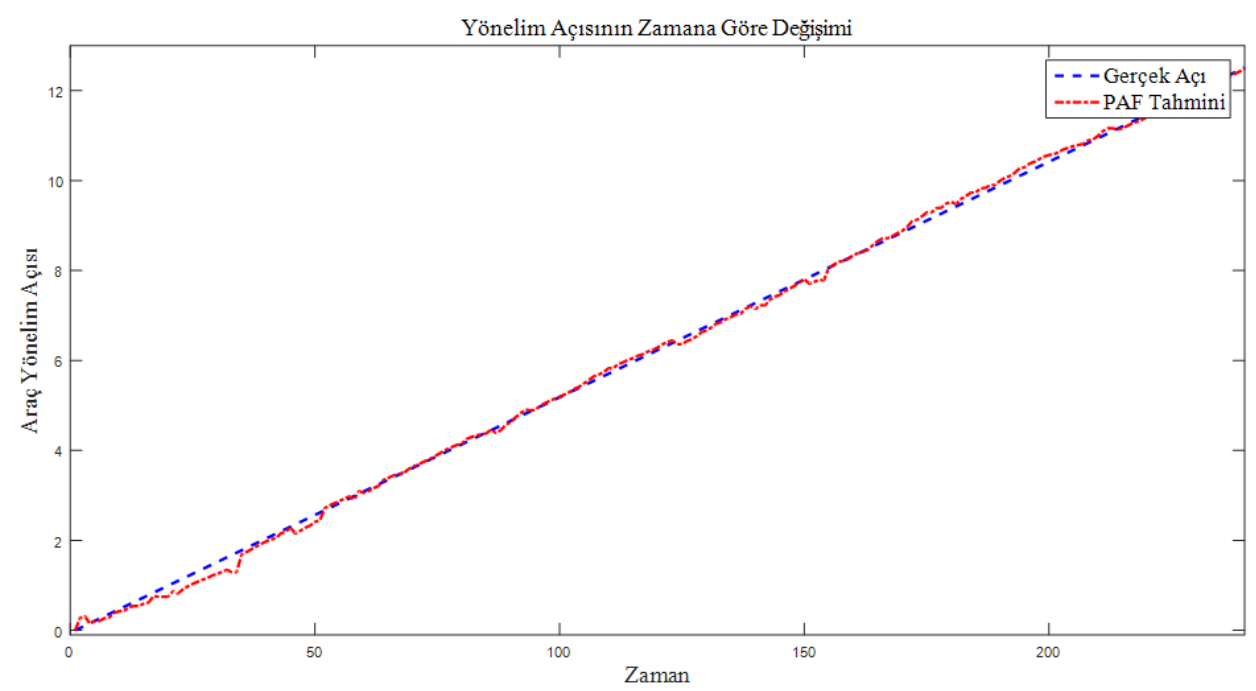

Şekil 10. PAF tabanlı EZKH araç yönelim açısı değişimi (PFF based SLAM heading angle variation) 


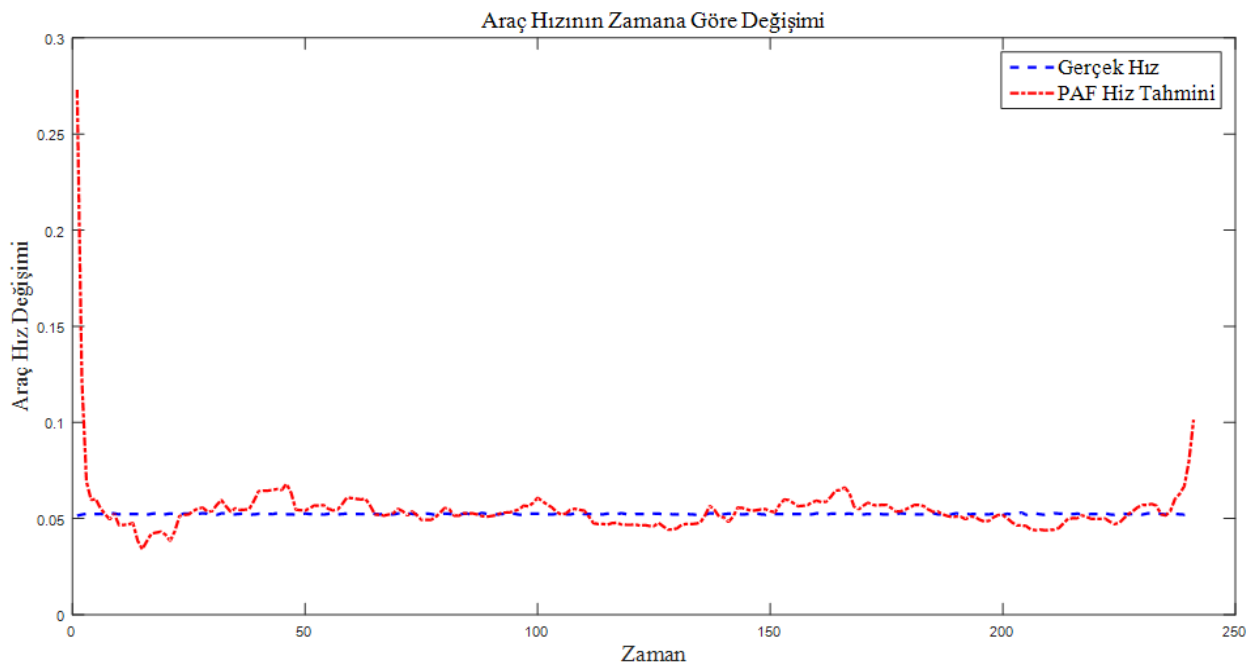

Şekil 11. PAF tabanlı EZKH - Araç hız değişimi (Particle flow filter based SLAM - Velocity variation)

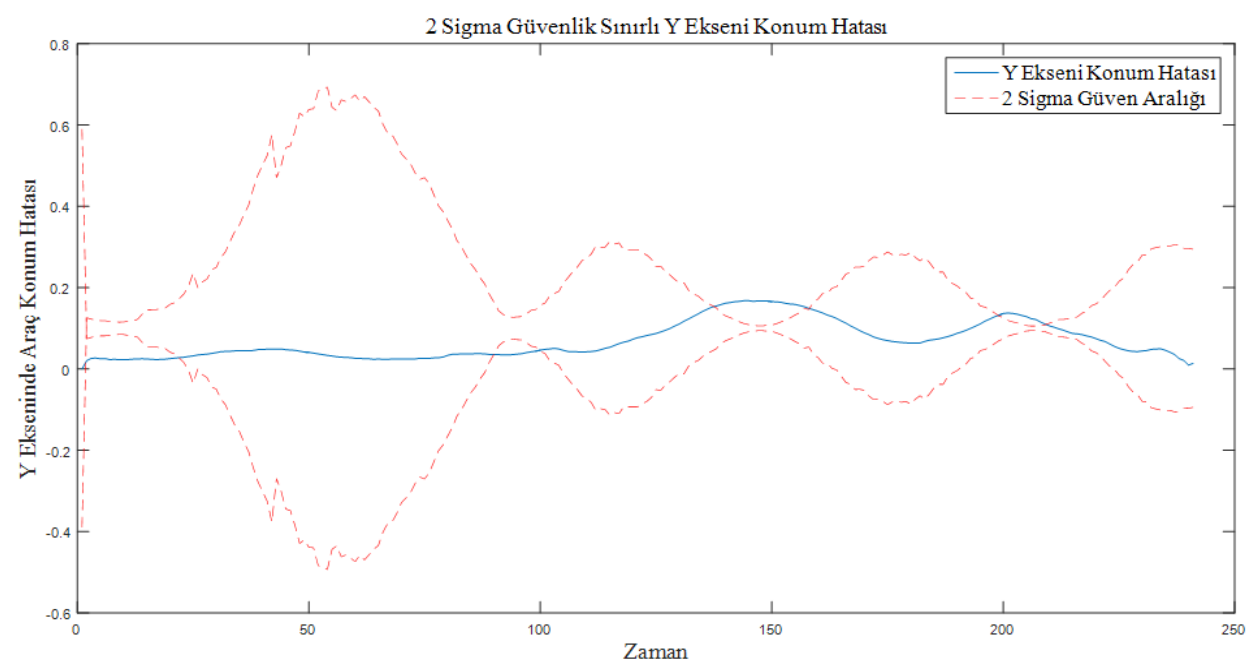

Şekil 12. PAF tabanlı EZKH araç Y ekseni konum hatası (Particle flow filter based SLAM Y-Axis position error)

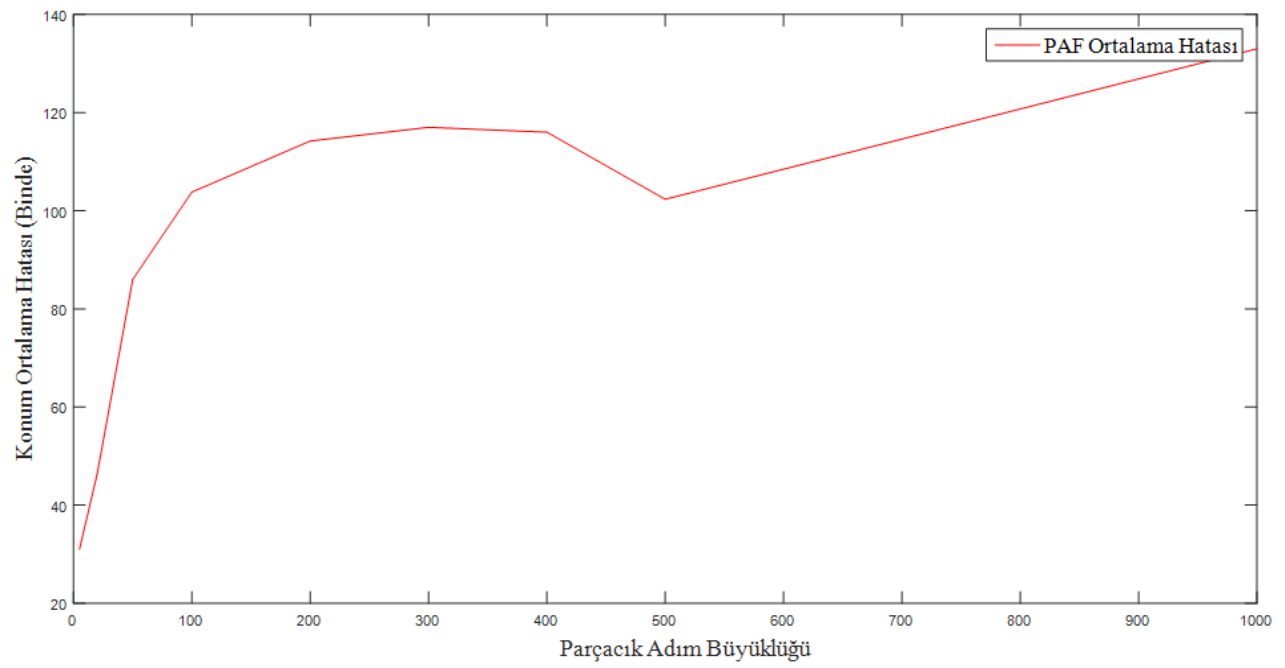

Şekil 13. Parçacık akış adımı büyüklüğü değişimi ve performans (Particle flow step size versus Average State Error) 


\subsection{EZKH Yöntemleri Performans Analizleri \\ (Performance Analysis of SLAM Methods)}

Bu bölümde EZKH probleminde tahmin yöntemleri genel karşılaştırması için temel olarak literatürde hakim olan genişletilmiş Kalman filtresi ve parçacık filtresi yanında önerilen parçacık akış filtresi ele alınacaktır. GKF'nin özellikle mevcut araç konumu ve işaretçi nesne konumlarından robotun soncul olasılığını daha doğru tahmin etmesinin yanında iyi bir araç hareket (sistem) modeli ve algılayıcı (sensör) gürültü bilgisi ile her adımda (m) işaretçi nesne boyutunun karesi kadar $\mathrm{O}\left(\mathrm{m}^{2}\right)$ verinin işlenerek kovaryans matrisinin yeniden olusturulması gerektirdiği bilinmektedir. Parçacık filtresi yaklaşımları ise sağladıkları tahmin doğruluğuna rağmen genel olarak $n$ adet parçacık için $\mathrm{O}(\mathrm{nm})$ ya da veri eşleştirmeleri sonrası $\mathrm{O}(\mathrm{n} \operatorname{logm})$ işlem yükü oluşturmaktadır. Bunun yüksek parçacık sayısı ihtiyacı düşünüldüğünde filtrenin elini zayıflattığı söylenebilir.

Literatürde verilen sonuçlara göre yapılacak en genel değerlendirmede sıkıştırılmış ya da ilave işlemci prosesleriyle hızlandırılmış yöntemleri bir kenara koymak şartıyla problemin türüne göre işaretçi sayısı ve kinematik model karmaşıklığ fazla olan durumlarda parçacık filtresi temelli yaklaşımların GKF ve DKF göre daha doğru ancak işlem yükü nedeniyle daha yavaş sonuçlar verdiği söylenebilir. $\mathrm{Bu}$ nedenle problem türüne uyarlanmış yöntemler ile değiştirilmiş ve genişletilmiş yöntemlerin kullanıldığı sıça görülmektedir. Paralel mimari avantajlarının her zaman kullanılmak istenmesinin yanında yine senaryo uyumlu olmak kaydı ile gerçek zamanlı işlenebilir yaklaşımlar tercih edilirken görüntü tabanlı yöntemler söz konusu kaygılarla gerçek zamanlı olmayan (off line) uygulamalarda daha çok kabul görmektedir. Gerek bu çalışma bulgularından gerekse literatürde geçen sonuçlardan derlenmiş genel değerlendirme, mevcut EZKH yaklaşımlarında durum/parametre tahmini için kullanılan yöntemler ile kullanılan algılayıcılar ve bulundukları ortama göre Tablo 1'de sunulmuştur.

GKF ve DKF belirsizlik çözümünde başarılı olurken yüksek boyutlu harita ve araç modeli söz konusu olduğunda işlem zamanı sorunu ile karşılaşmaktadır. Bunun dışında araç ve gözlem modeli gürültülerinin normal dağıldıklarını kabul ettiğinden bunun dışında dağılan gürültülerde performansları düşmektedir. Parçacık filtreleri ise doğrusal olmayan araç modelleri ve normal dağılımlı olmayan gürültüler için çözüm üretmekle beraber özellikle yüksek boyutlu harita ve araç modeli için hem doğruluk hem de işlem yükü ve zamanı konusunda bünyesinde sorunlar barındırdığından gerçek zamanlı uygulamalarda tercih edilmezler. Benzetim sonuçlarında Şekil 8 ile de görüldüğü gibi parçacık akış filtresinin ise sağladığı doğruluk yakınsaması yanında artan işlem yükü göze çarpmaktadır.

\section{SONUÇLAR VE TARTIŞMALAR (RESULTS AND DISCUSSIONS)}

Günümüz ve belki de gelecek insansız sistemleri için güvenli bir otonom seyrüsefer yapabilmenin vazgeçilmez ön koşulu olan araç konum bilgisinin doğru şekilde belirlenmesi hali hazırda küresel uydu yönbulum sistemleri yardımıyla gerçekleştirilmektedir. Ancak bu sistemlerin olmadığ savaş, doğal afet veya coğrafi koşullar nedeniyle bunlara erişilemediği ortamlarda alternatif bir çözüm ihtiyacı bir süredir araştırmacıları meşgul etmiş olmakla birlikte seyrüsefer yapılan bölgenin haritasının da bilinmemesi durumunda güvenli konum belirlemek oldukça zor bir problem olarak belirmektedir.

Eş Zamanlı Konumlama ve Haritalama bu duruma çare olmak düşüncesiyle ortaya çıkmış olmakla birlikte aynı anda hem platform konumu hem de ortam haritası belirlenmesi yöntemine verilen addır. Bu yöntemde uzun süre Kalman ve

Tablo 1. EZKH yöntemleri ve genel performans analizleri (Performance analysis of SLAM methods)

\begin{tabular}{|c|c|c|c|}
\hline Method & $\begin{array}{l}\text { Genişletilmiş/Dağıtılmış } \\
\text { Kalman filtresi }\end{array}$ & Parçacık filtresi & $\begin{array}{l}\text { Parçacık akış } \\
\text { filtresi }\end{array}$ \\
\hline Platform & \multicolumn{3}{|c|}{$\begin{array}{c}\text { Kara/deniz/hava insansız sistemleri } \\
\text { Homojen ve heterojen çoklu araçlar } \\
\text { İnsans1 robotlar }\end{array}$} \\
\hline Alg1layıc1 & \multicolumn{3}{|c|}{$\begin{array}{c}\text { Lazer,Sonar,Ultrasonik,Radar,Lidar } \\
\text { Kamera (Mono-stereo görme) } \\
\text { Ataletsel /INS/ Inertial Measurement Unit-IMU } \\
\text { Jiroskop, Akselerometre, Odometri }\end{array}$} \\
\hline Kullanım & \multicolumn{3}{|c|}{$\begin{array}{c}\text { Otonomi, Askeri - sivil hizmet sektörü uygulamaları, } \\
\text { Deniz ve yer altı incelemeleri (petrol, maden, sismik araștırmaları gibi) }\end{array}$} \\
\hline Değerlendirme & $\begin{array}{l}\text { Hata az, hızlı } \\
\text { Normal dağılmayan belirsizliklerde başarısı } \\
\text { düşük } \\
\text { Ölçüm belirsizliklerden etkilenmez } \\
\text { Ancak yapısında tutarsızlıklar var }\end{array}$ & $\begin{array}{l}\text { Hata daha az } \\
\text { Doğrusal olmayan araç } \\
\text { modeli ve belirsizlikte } \\
\text { başarılı } \\
\text { Ancak boyut } \\
\text { büyüdükçe hatalı ve } \\
\text { yavaş }\end{array}$ & $\begin{array}{l}\text { Hata daha az } \\
\text { Basit yapılı, kararlı } \\
\text { Parçacık filtresinin başarısız } \\
\text { olduğu } \\
\text { düşük ölçüm belirsizliklerde } \\
\text { daha başarılı } \\
\text { Ancak boyut büyüdükçe } \\
\text { hatalı ve yavaş }\end{array}$ \\
\hline
\end{tabular}


parçacık filtresi gibi yaygın yöntemler durum tahmin adımları için kullanılmış, model ya da grafik tabanlı üst seviye kontrol yöntemleri ve özellikle görüntü işleme teknikleri ise bu kapsamda ortaya çıkan veri birleştirme ya da döngü kapama sorunlarına kara, deniz, hava platformları için çözüm olarak düşünülmüştür. Bununla birlikte eş zamanlı konum belirleme ve haritalama probleminde (ya da altenatif çözüm arayışlarında denilebilir) son çeyrek yüzyıl gibi bir zaman içinde ortaya çıkan bilgiyi derleyerek gelinen noktayı anlama ihtiyacı nedeniyle tahmin yöntemi, platform yapısı, araç ve algılayıcı tipi ile ortam türü başlıklarında sinıflandırma yoluyla performans analizi ortaya koyma gerekliliği belirmiştir.

Bu çalışma genel olarak EZKH yöntemlerinin performans analizleri yanısıra literatürde ilk kez Parçacık Akış Filtresi Tabanlı Eş Zamanlı Konum Belirleme ve Haritalama (PAFEZKH) yaklaşımını ortaya koymak amacında olmuştur. Önerilen yöntemin insansız kara sistemlerinde uygulanabilirliği incelenmiş olup hava ve denizaltı gibi platformlardaki performansları gelecek çalışmalar arasında planlanmıştır. Bu çalışmanın devamında yine ilk defa PAF filtresinin tutarlılığı analiz edilecek ve durum tahmin başarısının yanısıra uzun süreli navigasyonlarda birikimli hatalara yol açan, parçacık akış filtre algoritmasında parallel biçimde işleyen ve parçacıkların akış miktarlarını belirlemede etkin olan kovaryans ve gözlem matrislerini yapısında bulunduran genişletilmiş Kalman filtresi kaynaklı tutarsızlıklar belirtileri ile ortaya konulacaktır. Parçacık akiş filtresi ile birlikte literatürde bahsi geçen diğer tahmin yöntemleri birer insansız kara platformu üzerinde off-line testlere tabi tutularak sonuçları değerlendirilmiştir. Benzetim sonuçları parçacık akış filtresi tabanlı EZKH performansının parçacık sayısı, parçacık migrasyon (akış) adımı, süreç ve ortam gürültüleri gibi parametrelere bağlı olarak literatürde daha önce yer almış diğer tahmin yöntemlerine göre üstünlükler taşıdığı ve doğruluk (accuracy) açısından daha iyi sonuçlar verdiğini ancak hesaplama maliyeti açısından bazı gerçek zamanlı uygulamalar için kırılganlıklarının olabileceğini göstermiştir. Bununla birlikte filtrenin özellikle belirsizlikleri düşük algılayıcılar kullanan ölçüm ortamlarında parçacık filtresi yapısında ortaya çıkan dejenerasyon sorununu ortadan kaldırarak daha başarılı sonuçlar vermesi nedeniyle tercih edilebileceği görülmüştür. Özellikle Cadena vd. [33] ile Huang ve Dissanayake [35] tarafından gelecek çalışmalarında öngörüldüğü üzere sonraki EZKH araştırmaları içerisinde gerçek zamanlı (realtime) testlerle önerilen yöntemin hesaplama maliyetlerini daha net ve ayrıntılı ortaya koymak mümkün olabilir.

\section{KAYNAKLAR (REFERENCES)}

1. Smith R., Cheesman P., On the representation of spatial uncertainty, Int. J. Rob. Res., 5 (4), 56-68, 1987.

2. Dissanayake G., Durrant-Whyte H.F., Bailey T., A computationally efficient solution to the simultaneous localisation and map building (SLAM) problem, ICRA IEEE International Conference of Robotics and
Automation, San Francisco, California USA, 10091014, 24-28 April, 2000.

3. Bailey T., Durrant-Whyte H.F., Simultaneous localization and mapping (SLAM): The Essential Algorithms, IEEE Robotics and Automation Magazine, 13 (2), 99-105, 2006.

4. Bailey T., Durrant-Whyte H.F., Simultaneous localization and mapping (SLAM): State of the Art, IEEE Robotics and Automation Magazine, 13 (2), 105$110,2006$.

5. Andrade-Cetto J., Sanfeliu A., The effects of partial observability in SLAM, ICRA IEEE International Conference of Robotics and Automation, 397-402, New Orleans, Los Angeles USA, 26 April -1 May, 2004.

6. Vidal-Calleja T., Andrade-Cetto J., Sanfeliu A., Conditional for suboptimal filter stability in SLAM, IEEE Inernational Conference on Intelligent Robots and Systems, 27-32, Sendai, Japan, 28 Sept -2 Oct, 2004.

7. Bailey T., Nieto J., Guivant J., Stevens M., Nebot E., Consistency of the EKF-SLAM algorithm, IROS IEEE/RSJ International Conference on Intelligent Robots and Systems, 3562-3568, Beijing, China, 9-15 Oct, 2006.

8. Kim J., Sukkarieh S., Airborne Simultaneous Localisation and Map Building, ICRA IEEE International Conference of Robotics and Automation, 406-411, Taipei, Taiwan, 14-19 Sept, 2003.

9. Johnson E. N., Allen D.W., Kaess M., Chowdhary F.G., Autonomous flight in GPS-denied environments using monocular vision and inertial sensors, Journal of Aerospace Information Systems, 10 (4), 172-186, April 2013.

10. Spruyt V., Ledda A., Philips W., Sparse optical flow regularization for real-time visual tracking, ICME IEEE International Conference on Multimedia and Expo, 1-6, San Jose, California USA, 15-19 July, 2013.

11. Songmin J., Xiaolin Y., Xiuzhi L., Mobile robot parallel PF-SLAM based on OpenMP, ROBIO IEEE International Conference on Robotics and Biomimetics, 508-513, Guangzhou, China, 11-14 Dec, 2012.

12. Welle J., Schulz D., Bachran T., Cremers A.B., Optimization techniques for laser-based 3D particle filter SLAM, ICRA IEEE International Conference on Robotics and Automation, 3525-3530, Alaska USA, May, 2010.

13. Xiuzhi L., Songmin J., Ke W., Xiaolin Y., Distributed parallel processing of mobile robot PF-SLAM, ACAI International Conference on Automatic Control and Artificial Intelligence, 927-930, Xiamen, China, 3-5 Mar, 2012.

14. Martin F., Haiyang Z., CUDA accelerated robot localization and mapping, TePRA IEEE International Conference on Technologies for Practical Robot Applications, 1-6, Woburn, MA, USA, 22-23 April 2013.

15. Yoona S., Hyunga S., Leea M., Roha K.S., Ahna S., Geeb A., Bunnunb P., Calwayb A., Mayol-Cuevasb W.W., Real-time 3D simultaneous localization and 
map-building for a dynamic walking humanoid robot, Adv. Rob., 27 (10), 759-772, 2013.

16. Bibby C., Reid I., A Hybrid SLAM Representation for Dynamic Marine Environments, IEEE International Conference on Robotics and Automation, 257-264, Anchorage, AK, USA, 3-7 May 2010.

17. Aditya A., Implementation of a $4 D$ fast SLAM including volumetric sum of the UAV, ICST International Conference on Sensing Technology, 78-84, Kolkata, India, 18-21 Dec, 2012.

18. Oğuz A.E., Temeltaş H., Extended kalman filter based airborne simultaneous localization and mapping, Journal of Aeronautics and Space Technologies, 6 (2), 69-74, 2013.

19. Vidal-Calleja T., Andrade-Cetto J., Sanfeliu A., Estimator stability analysis in SLAM, IAV2004 IFAC Symposium on Intelligent Autonomous Vehicles, 3337, Sendai, Japan, 28 Sept-2 Oct, 2004.

20. Zhang L., Meng X., Chen Y., Convergence and consistency analysis for FastSLAM, IEEE Intelligent Vehicles Symposium, 447-452, Xi'an, China, 3-5 June, 2009.

21. Julier S.J., Uhlman J.K., Simultaneous localisation and map building using split covariance intersectio, International Conference on Intelligent Robots and Systems, 1257-1262, Maui, HI USA, 29 Oct-3 Nov, 2001.

22. Castellanos J.A., Neira J., Tardos J.D., Limits to the consistency of EKF-Based SLAM, IAV2004 IFAC Symp. on Intelligent Autonomous Vehicles, Sendai, Japan, 28 Sept-2 Oct, 2004.

23. Huang S., Disanayake G., Convergence and consistency analysis for extended kalman filter based SLAM, IEEE Trans. Rob., 23 (5), 1036-1049, 2007.

24. Huang G.P., Mourikis A.I., Roumeliotis S.I., Observability-based Rules for Designing Consistent EKF SLAM Estimators, Int. J. Rob. Res., 29 (5), 502528, April 2010.

25. Hesch J.A., Dimitrios G.K., Bowman S.L., Roumeliotis S.I., Observability-constrained vision-aided inertial navigation, University of Minnesota MARS Lab Technical Report, Minneapolis, MN, USA, Feb 2012.

26. Yang P., Efficient particle filter algorithm for ultrasonic sensor-based 2D range-only simultaneous localisation and mapping application, IET Journals \& Magazines, Wireless Sensor Systems, 2 (4), 394- 401, 2012.

27. Mohan M., Krishna M.K., Mapping large scale environments by combining particle filter and information filter, ICARCV International Conference on Control Automation Robotics \& Vision, 1000-1005, Singapore, 7-10 Dec, 2010.

28. Thurn S., Thayer S., Whittaker W., Baker C., Burgard W., Ferguson D., Hahnel D., Montemerlo M., Morris A., Omohundro Z., Reverte C., Autonomous exploration and mapping of abandoned mines, IEEE Rob. Autom. Mag., 11 (4), 79-91, 2004.

29. Guivant J., Nebot E., Optimization of the simultaneous localization and map building algorithm for real time implementation, IEEE Transaction on Robotics and Automation, 17 (3), 242-257, 2013.

30. Shan L., Ya H.X., Xiao L.X., Ning H.Z., Simulation research on multi-robot SLAM of information filter, Advances in Mechatronics and Control Engineering Applied Mechanics and Materials, 278, 280, January 2013.

31. Xiaodong L., Aouf N., Experimental research on cooperative vSLAM for UAVs, CICSyN International Conference on Computational Intelligence Communication Systems and Networks, 385-390, Madrid, Spain, 5-7 June, 2013.

32. Liping Q., Hongjian W., An overview of Robot SLAM problem, CECNet International Conference on Consumer Electronics, Communications and Networks, 1953-1956, XianNing, China, 16-18 April, 2011.

33. Cadena C., Carlone L., Carrillo H., LatifY., Scaramuzza D., Neira J., Reid I.D., Leonard J.J., Past, Present, and Future of Simultaneous Localization and Mapping: Towards the Robust-Perception Age, IEEE Trans. Rob., 32 (6), 1309-1332, 2016.

34. Du J., Carlone, L., Kaouk N.M., Bona B., Indri M., A comparative study on active SLAM and autonomous exploration with particle filters, AIM IEEE/ASME International Conference on Advanced Intelligent Mechatronics, 916-923, Budapest, Hungary, 3-7 July, 2011.

35. Huang S., Dissanayake G., A critique of current developments in simultaneous localization and mapping, Int. J. Adv. Rob. Syst., 13 (5), 1-13, 2016.

36. Monjazeb A., Sasiadek, J.Z., Necsulescu D., Autonomous navigation among large number of nearby landmarks using FastSLAM and EKF-SLAM - A comparative study, MMAR International Conference on Methods and Models in Automation and Robotics, 369374, Miedzyzdroje, Poland, 22-25 August, 2011.

37. Rigatos G.G., Technical analysis and implementation cost assessment of sigma-point kalman filtering and particle filtering in autonomous navigation systems, VTC IEEE Vehicular Technology Conference, 1-5, Taipei, Taiwan, 16-19 May, 2010.

38. Daum F., Huang J., Particle flow for nonlinear filters, Bayesian decisions and transport, FUSION International Conference on Information Fusion, 1072-1079, Istanbul, Turkey, 9-12 July, 2013.

39. Ding T., Coates, M.J., Implementation of the DaumHuang exact-flow particle filter, SSP IEEE Statistical Signal Processing Workshop, 257-260, Ann Arbor, MI, USA, 5-8 August, 2012.

40. Jilkov V.P., Jiande W., Huimin C., Performance comparison of GPU-accelerated particle flow and particle filters, FUSION International Conference on Information Fusion, 1095-1102, Istanbul, Turkey, 9-12 July, 2013.

41. Charalampidis D., Jilkov V. P., Wu J., Implementation and performance of FPGA-accelerated particle flow filter, SPIE Society of Photo-Optical Instrumentation Engineers, Signal and Data Processing of Small Targets, 9596, San Diego, California, USA, 2015. 
42. Avcı K., Kaiser-Hamming window and its performance analysis for nonrecursive digital filter design, Journal of the Faculty of Engineering and Architecture Gazi University, 29 (4), 823-833, 2014.

43. Karaboğa N., Kamışlıoğlu B., A new method for quarter mirror filter bank design, Journal of the Faculty of
Engineering and Architecture Gazi University, 30 (2), 297-307, 2015.

44. Hanafi D., Abueejela Y. M., Zakaria M.F., Wall follower autonomous robot development applying fuzzy incremental controller, Intelligent Control and Automation, 4 (1), 18-25, 2013. 